Vol.15, No. 54, January 2020, 13- 32

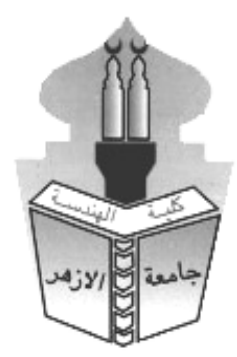

\title{
ANALYTICAL AND EXPERIMENTAL STUDY OF THIN CIRCULAR STEEL TUBES UNDER BENDING
}

\author{
Maheeb M. E. Abdel-Ghaffar*, Eslam Y. Gomaa and Sherif A. Mourad \\ Structural Engineering Department, Faculty of Engineering, Cairo University, Giza, Egypt \\ *Corresponding Author E-mail: CairoSteel@yahoo.com
}

\begin{abstract}
Available studies that compare experimental with analytical bending capacity of thin-walled circular tubes are few. A wide difference is noticed between experimental and analytical results especially for thin-walled tubes. Trying to fill this gap, experimental and analytical bending capacities of circular tubes are reviewed. A parametric study is conducted to predict the allowable bending stresses and slenderness ratios that separate between section types: compact, non-compact and slender. Four full-scale tubes are tested up to failure under bending: two cantilever beams with one concentrated load at the free end; and two simple beams with concentrated loads at the one-third points. Verification of the 3D non-linear finiteelement analysis against the experimental results is conducted to ensure analysis accuracy. In addition, comparison between the procedures used for bending capacity calculations in different codes and research studies is performed. Distribution of stresses and overall versus local buckling modes are investigated. Parameters studied include: Diameter to thickness (D/t) ratio, Length to Diameter (L/D) ratio, load conditions, support conditions and stressstrain curves.
\end{abstract}

KEYWORDS : Thin-Walled, Circular Tubes, Nonlinear Analysis, Testing, Buckling

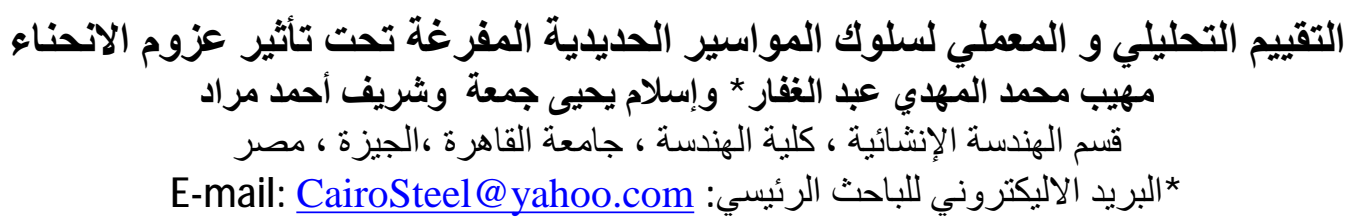

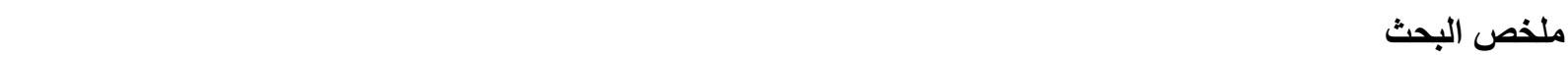

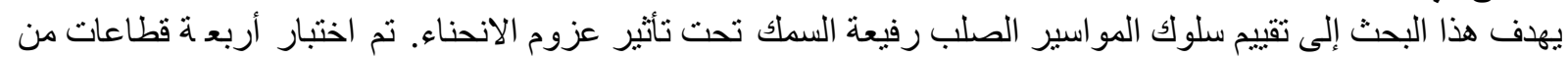

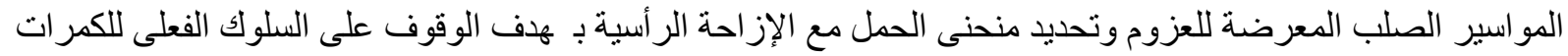

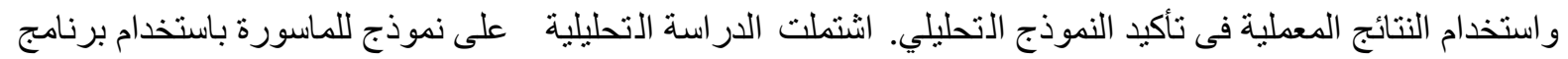

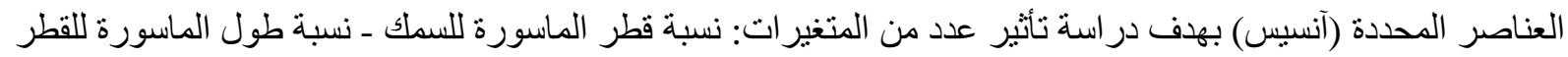
ـ أسلوب التحميل - طريقة تمثيل الركائز. وقد نم الوصول إلى معادلة مقترحة دقيقة لحساب الإجهاد الأقصى للمو اسير الكير

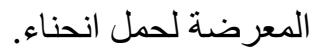
الكلمات المفتاحية : المواسير الصلب ، التحليل اللاخطى ، اختبارات عملية ، التقوس ، الانحناء

\section{INTRODUCTION}

Thick and thin tubes are widely used in construction.Thick tubes are used in telecommunication and transmission towers, lighting columns, traffic signs, piles, wind bracing, axially loaded columns and pipelines. Thin tubes are used in wind turbine towers and 
chimneys. Circular hollow steel sections are usually classified according to their slenderness ratios D/t. Some codes classify them by the slenderness ratios as $\lambda_{\mathrm{s}}=\mathrm{D} / \mathrm{t}^{*}\left(\mathrm{~F}_{\mathrm{y}} / 250\right)$ where $\mathrm{F}_{\mathrm{y}}$ is yield stress in MPa.

The failure mode shapes of steel tubes under bending are: ovalisation, smooth kink, wall wrinkles (wave-buckling) and local buckling. The tube ovalisation phenomena is a reduction in the tube cross section during the loading process whereas the circular section bec omes an ellipse section during and after applying the load through the tube whole length with maximum deformed shape at the mid-span. As known, the ellipse inertia $I_{x}$ is less than the circular inertia. Therefore, the relation between moment and curvature is non-linear. Hence, the failure moment will be accelerated. This failure mode occurs to the compact sections. Smooth kink problem is similar to ovalisation; but the tube cross section at the location of maximum moment is deformed sharply and suddenly. This failure mode comes to noncompact sections. The wall wrinkles are a series of buckling waves at the compression side of the tube section. These waves may be one wave (bulge) or many waves, depending on the loading and supporting conditions. This failure mode takes place for compact and noncompact sections. Local buckling in the tube wall at the ultimate load position happens for slender sections.

Unlike thick-walled tubes, little experimental and analytical research exists for thin-walled tubes (slender sections). Egyptian and other international codes such as: (ANSI/AISC 2010), (AS4100 1998) and (ASCE/AWEA 2011) have significant differences among their slenderness limits that identify section classification. They also provide different equations that give different values for the ultimate bending moment capacity of such tubes.

This research aims at: a) evaluating the tubes bending capacities, slenderness limits D/t, L/D and yield stress effects of circular steel hollow sections through analytical and experimental investigation; b) conducting a comparison between the ultimate bending and the slenderness limits in various codes; and c) suggesting new slenderness limits and simple bending capacity equations according to research results.

A pioneer experimental and theoretical study was conducted by (Brazier 1927). He presented the phenomenon of ovalisation of circular hollow sections. Many mathematical equations and assumptions were used to obtain the ultimate moment capacity $M_{u l t}$ that the tube can achieve under bending:

$$
M_{u l t}=\frac{2 \sqrt{2}}{9} \frac{E \pi R t^{2}}{\sqrt{1-v^{2}}} \approx 1.035 E t^{2} R
$$

Brazier, 1927

where $\mathrm{E}$ is the modulus of elasticity, $\mathrm{t}$ is wall thickness, $\mathrm{R}$ is tube outer radius, and $v$ is Poisson's ratio.

On the other hand, the critical flexural capacity of thin-walled hollow tubular members that is caused by elastic local buckling was given by (Timoshenko 1961):

$$
M_{c r}=\frac{E}{\sqrt{3\left(1-v^{2}\right)}} \frac{t}{R} \pi R t^{2} \approx 1.9 E t^{2} R
$$

(2) Timoshenko, 1961

The compact and non-compact sections were studied experimentally by (Sherman 1976, 1986), (Schilling 1965), (Jirsa 1972), (Korol 1972). A unique pure bending ring was assembled to simulate the pure bending test without any influential axial and/or shear forces at the middle span of tested sample (Cimpoeru 1993) and was used in experimental study by (Elshalakani 2001 and 2002). A series of stainless steel cricular hollow sections was examined analytically and experimentally (Kiymaz 2005 and 2007). An analytical study was performed by (Sadowski 2013) to examine the availability and validity of using solid finite elements and shell finite elements to model the circular metal hollow sections under bending 
to predict the buckling behavior of thick tubes. The effect of section slenderness on the bending strength of thick and thin-walled cylindrical steel hollow tubes was studied by (Guo et. al 2013).

\section{FINITE ELEMENT MODEL AND VERIFICATION}

\subsection{General}

The finite element method was used as a numerical model in this study throughout a multipurpose finite element program, ANSYS. A three dimensional finite element models are used to evaluate the behavior of circular steel hollow sections which are subjected to bending moment. The circular steel tube is developed using shell element (SHELL181) which is suitable for analyzing thin to moderately-thick shell structures. It is a 4-node element with six degrees of freedom at each node: translations in the $\mathrm{x}, \mathrm{y}$, and $\mathrm{z}$ directions, and rotations about $\mathrm{x}, \mathrm{y}$, and $\mathrm{z}$ axes. SHELL181 is well-suited for linear, large rotation, and/or large strain nonlinear applications.

To evaluate the bending behavior of tubes, there are many ways to apply the loads and supports locations, however in this study, three models are used as follows: 1) Applying a concentrated bending moment through the beam ends, so in this case the beam is subjected to pure global bending. 2) Applying a two concentered moments at the middle part of a simply supported beam to gat pure bending only in the middle span. 3) Applying concentrated load at the free end of a long cantilever beam to reduce shear effect on the bending behavior.

\subsection{Model Verification}

This verification study is for experimental and analytical models for full scale two wind turbine towers specimens with the same dimensions and load conditions (Sim et. al 2014). The tested specimens slenderness ratio $\mathrm{D} / \mathrm{t}=333.3$ and $\lambda_{\mathrm{s}}=360$. The analytical study is done using the commercial finite element software (ABAQUS 2011), whereas the model is a cantilever beam with variable diameters starting from $D / t=200$ at the free end, then $D / t=267$ at the middle part, and finally $\mathrm{D} / \mathrm{t}=333$ at the fixed base end. The door opening of the towers is taken into considerations in this model. Moreover, the inner ring with vertical triangles stiffeners are modeled to simulate the fully tower stiffness. Furthermore, the inner connected rings at the middle parts are also taken into consideration.

The ANSYS model for specimen 1 presents a good correlation with ABAQUS model loaddisplacement curve. Moreover, they give almost the same maximum load capacity, as shown in Fig. 1. However, both models present a higher load capacity than the experimental specimen 1 results. The possible reason of this is that specimen 1 failure is in the anchor rods weld with the base-plate, which means that the tower itself was not collapsed. Therefore, the tower can reach a higher load capacity as ANSYS and ABAQUS models predicted.

Fig. 2 shows the buckling mode shapes of ABAQUS and ANSYS models. Both models show a good agreement with the shape of local buckling. However, the ABAQUS failure position is at the end of the first part of the tower, but the ANSYS failure position is at the start of the middle part of the tower. However, both models present inward and outward local buckling.

In spite of having similar failure mode-shapes, Specimen 2 load-capacity was $79 \%$ of Specimen 1. Local initial geometric imperfection of $19 \mathrm{~mm}$ dent had to be introduced at the same specimen local buckling failure position. ANSYS model presents a good correlation with the ABAQUS model and the experimental load-displacement curves, as shown in Fig. 3.

Fig. 4 shows failure mode shapes (analytical vs. experimental) of Specimen 2. Fortunately, there is good agreement. Local buckling is observed at the compression tower part toward the neutral axis. 


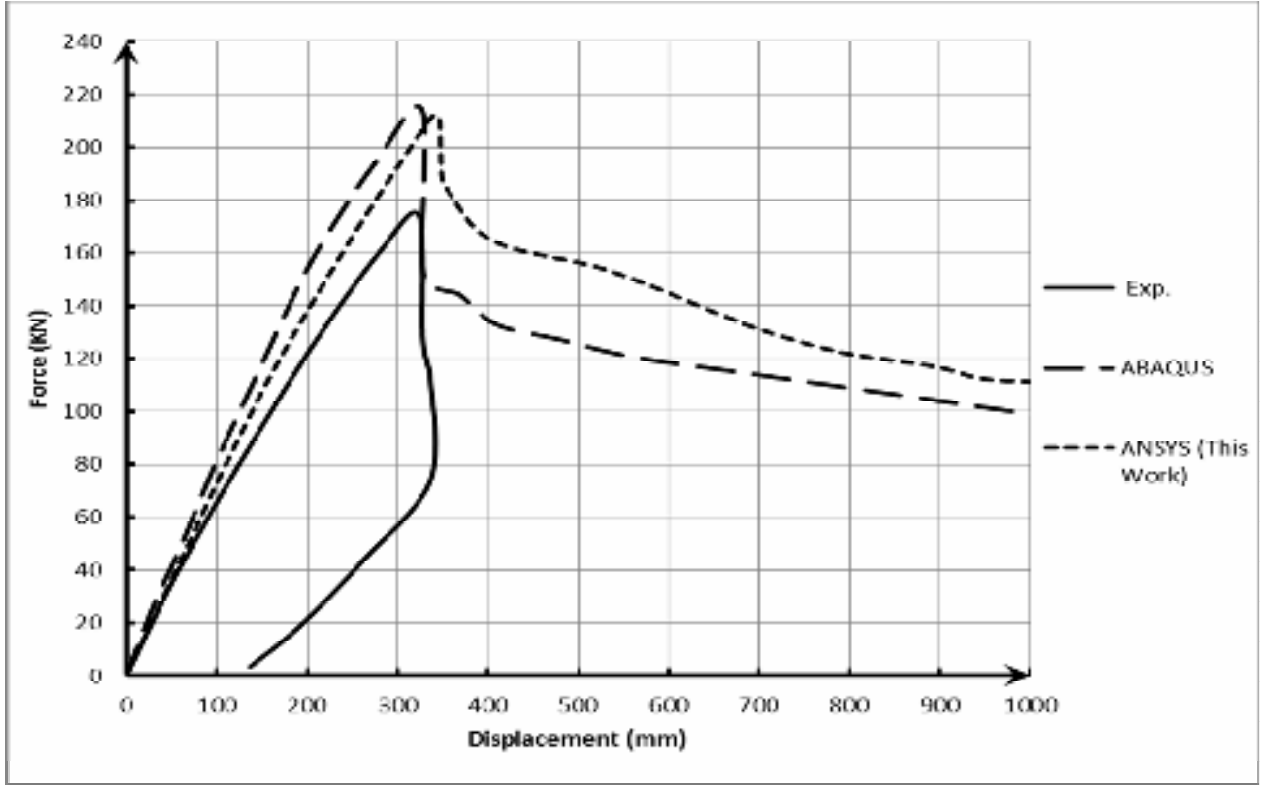

Figure 1: Specimen 1 load-displacement curves.
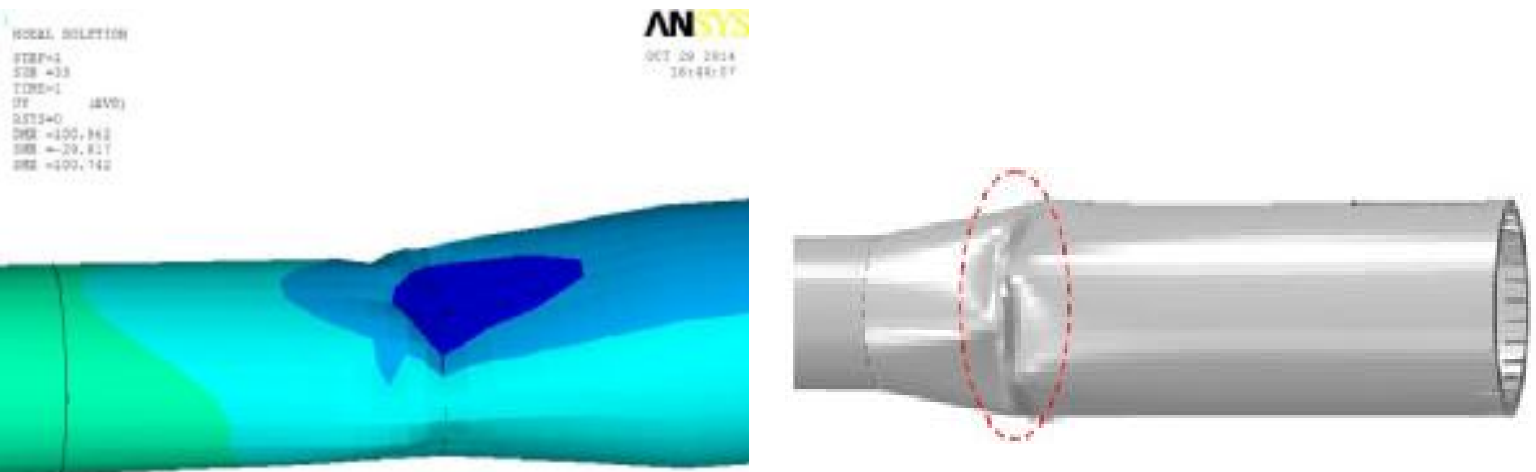

Figure 2: Failure mode shapes of Specimen 1.

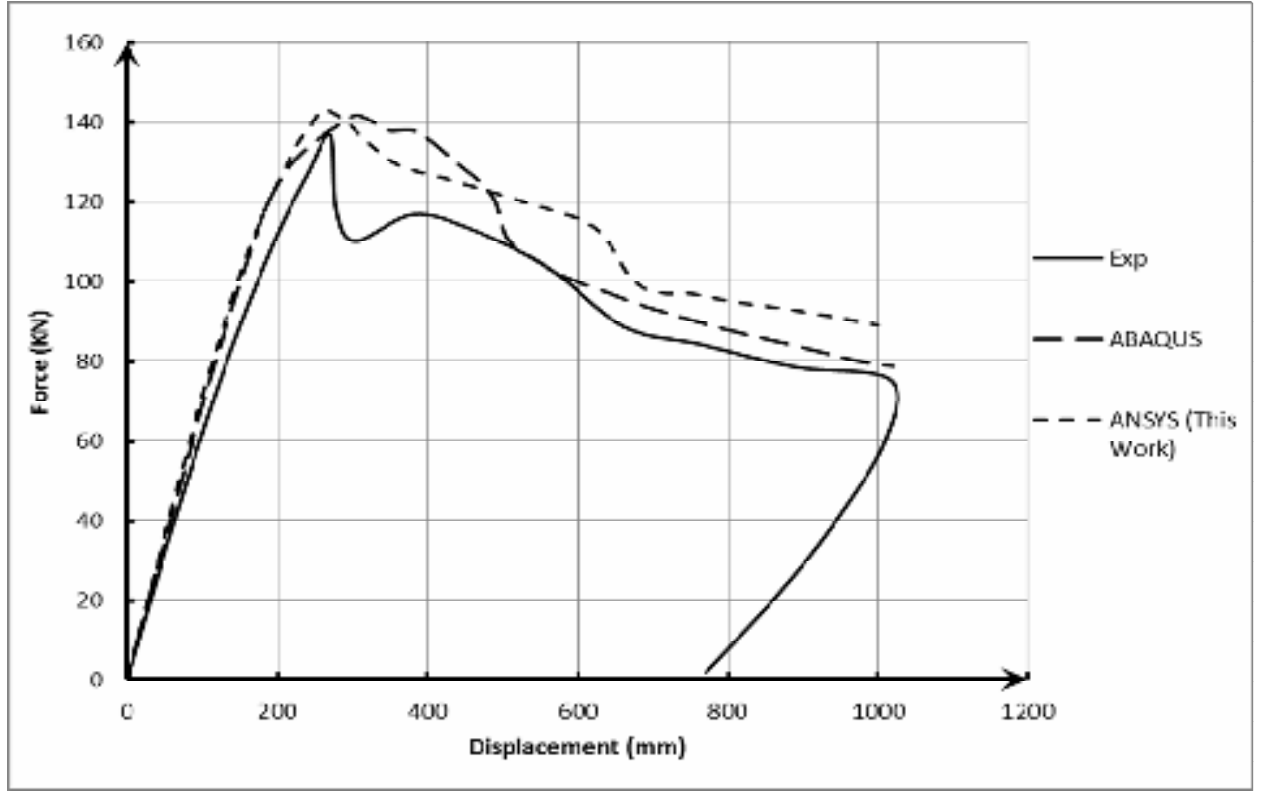

Figure 3: Specimen 2 load-displacement curves. 

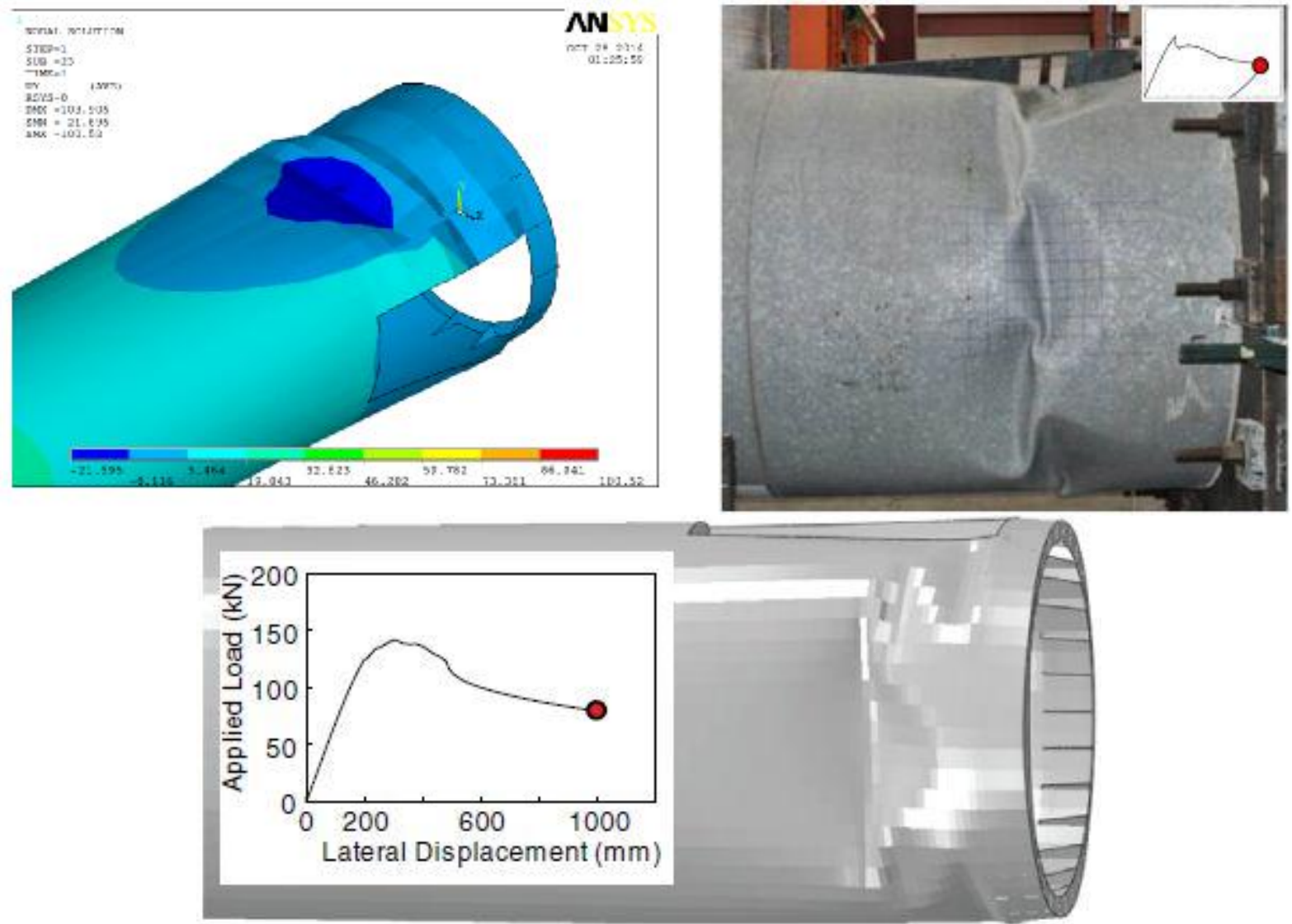

Figure 4: Failure mode shapes of Specimen 2.

\subsection{Elastic-Plastic model}

\subsubsection{Pure Bending Model}

The stress-strain curve for the steel material that is used in the finite element runs is assumed to be bilinear relationship. The yield stresses considered are ST37 $\left(2.4 \mathrm{t} / \mathrm{cm}^{2}\right)$ and ST52 $(3.6$ $\mathrm{t} / \mathrm{cm}^{2}$ ). Young's modulus $\mathrm{E}=2100 \mathrm{t} / \mathrm{cm}^{2}$ with strain-hardening slope after yield $=\mathrm{E} / 100$ and Poisson's ratio equal to 0.3 .

Loading and supporting mechanisms for pure bending is simulated by inserting a reference node at the start and end centers of each tube; then connecting this reference node with the tube nodes that are at the same plane by a rigid body (links). Therefore the applied moment is at the reference nodes, this moment is transferred to the tube wall at the end nodes of the tube through these rigid links. The tube supports conditions are simply supported hinged-roller beam as shown in Fig. 5.

A wide range of the $\mathrm{D} / \mathrm{t}$ ratio is performed to cover the three different section classifications: compact, non-compact and slender. Moreover, for studying the effect of $L / D$ ratio on the buckling mode-shapes and tubes bending capacities, the tubes are classified as short, medium and long. The geometries of the parametric study models are:

- $\mathrm{D} / \mathrm{t}=50,100,150,200,250,300$

- $\mathrm{L} / \mathrm{D}=3.5,5,7,10$

Fig. 6 shows the normalized moment $\left(M / M_{p}\right)$ curvature $\left(\kappa / \kappa_{\mathrm{y}}\right)$ curves of the $\mathrm{L} / \mathrm{D}=5$ model for the all $\mathrm{D} / \mathrm{t}$ ratios 50, 100, 150, 200, 250 and

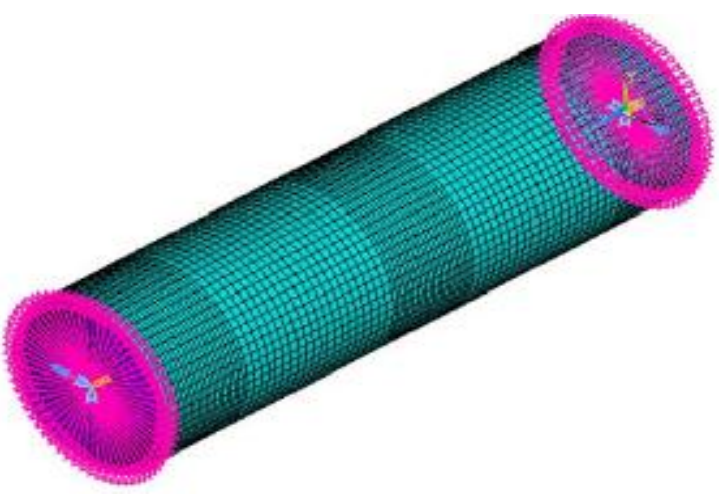

Figure 5: Pure bending Mesh for FEM 300 where This normalized curvature $\Phi$ is 
determined as the end rotation ratio $\beta$ by knowing that the yield end rotation $\beta_{\mathrm{y}}$ equal to $\left(\mathrm{LF}_{\mathrm{y}} / 2 \mathrm{ER}\right)$ It can be seen that the section rotation (curvature) capacity for the compact section $\mathrm{D} / \mathrm{t}=50$ is the highest capacity. However, the section rotation capacity for the slender section $\mathrm{D} / \mathrm{t}=300$ is the lowest capacity. It can be seen that for the lower $\mathrm{D} / \mathrm{t}$ values, the moment capacity is higher than the plastic moment because the used stress-strain curve has a slope equal to E/100 after the yielding point. Moreover, with respect to the section ultimate bending capacity, the $\mathrm{D} / \mathrm{t}$ model is the highest bending capacity because the $\mathrm{D} / \mathrm{t}$ is within the compact limits. However, the most slender section model $\mathrm{D} / \mathrm{t}=300$ is the lowest bending capacity.

Fig. 7 shows the failure mode shapes of the $\mathrm{L} / \mathrm{D}=5$ model for the all $\mathrm{D} / \mathrm{t}$ ratios $50,100,150$, 200,250 and 300 . It can be seen that the $\mathrm{D} / \mathrm{t}=50$ failure mode shape is an ovalisation at the mid-span the tube. However, the $\mathrm{D} / \mathrm{t}=100,150$ and 200 failure modes are outward bulge at the compression side of the beam because the tube length is short span. Moreover, the $\mathrm{D} / \mathrm{t}=$ 250 and 300 failure mode shapes are local buckling and sudden collapse.

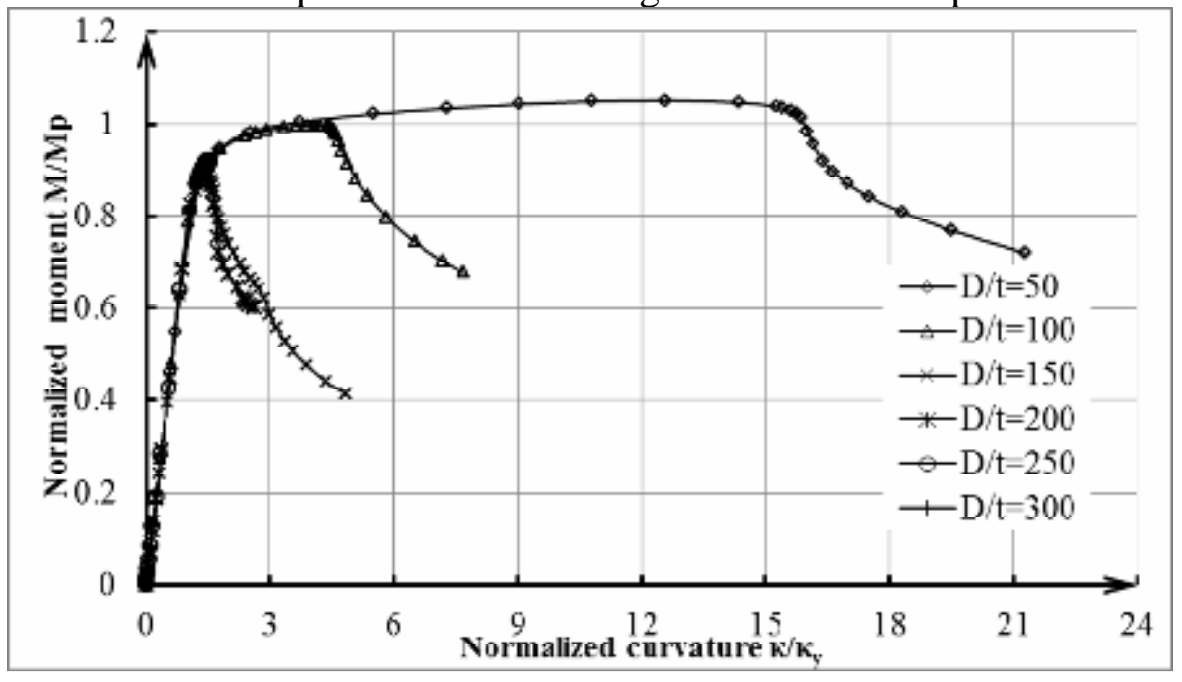

Figure 6: Normalized moment-curvature curves of L/D = 5 model for ST37.
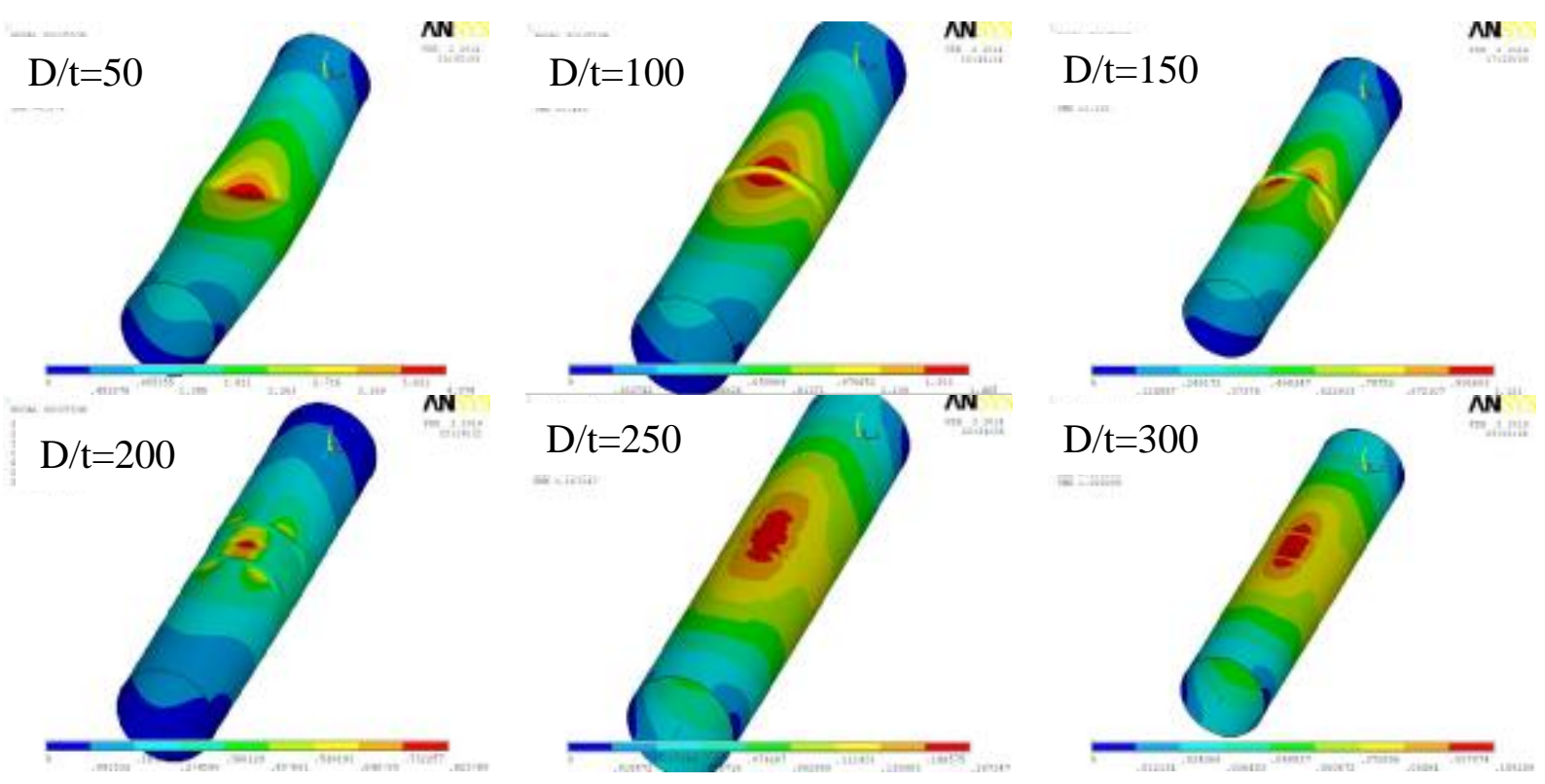

Figure 7: Failure mode shapes of $L / D=5$ model for all D/t ratios for ST37.

The total results normalized moment-curvature curves of all L/D ratios are summarized and presented in Fig. 8. It can be seen that the tube length is not affected on the tube bending capacity at the same $\mathrm{D} / \mathrm{t}$ ratio with differences within $5 \%$. Moreover, when the L/D ratio increases, the section rotation capacity will decrease at the compact sections only. However, for the non-compact and slender sections, the rotation capacity didn't differ for the L/D ratios 
(20\%). Fig. 9. shows a comparison between the rotation capacities of the tube section for the different L/D ratios.

In general, the curves of ST52 have the same shape and behavior as ST37. However, the ST37 results at the same $\mathrm{L} / \mathrm{D}$ and $\mathrm{D} / \mathrm{t}$ ratios for the compact and slender sections give higher ultimate bending and section rotation capacity than ST52 results but within $5 \%$, because the failure criteria is the ovalisation. Therefore, the ovalisation effect on the high steel grades is higher than the low steel grades. However, the slender sections results for both ST37 and ST52 almost give the same results, because the failure criteria for the slender section is wall local buckling.

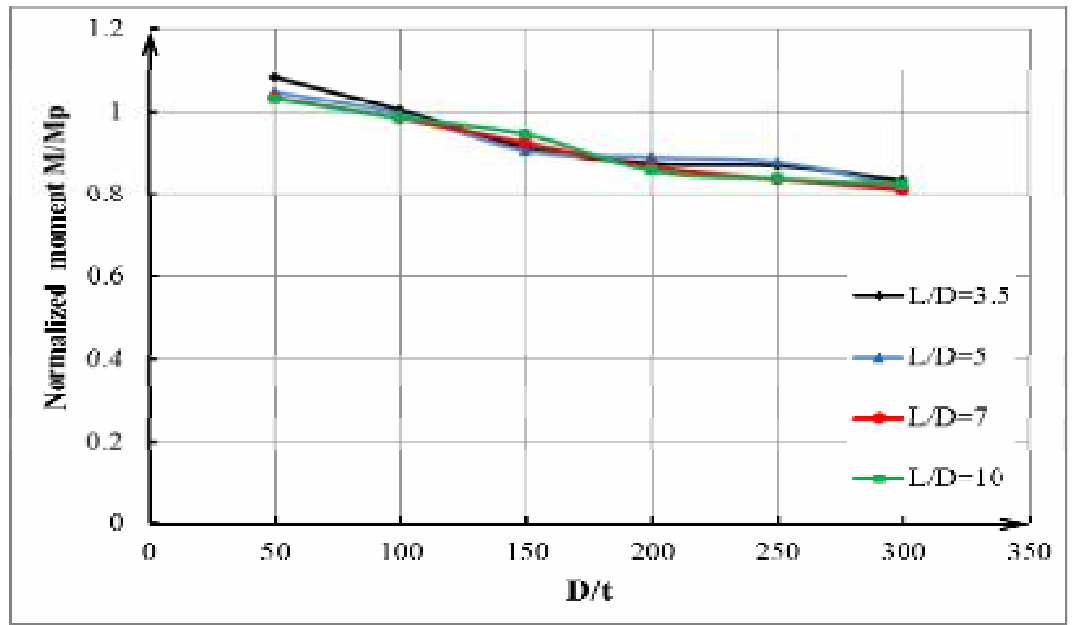

Figure 8: Normalized moment vs. D/t for all ST37 models.

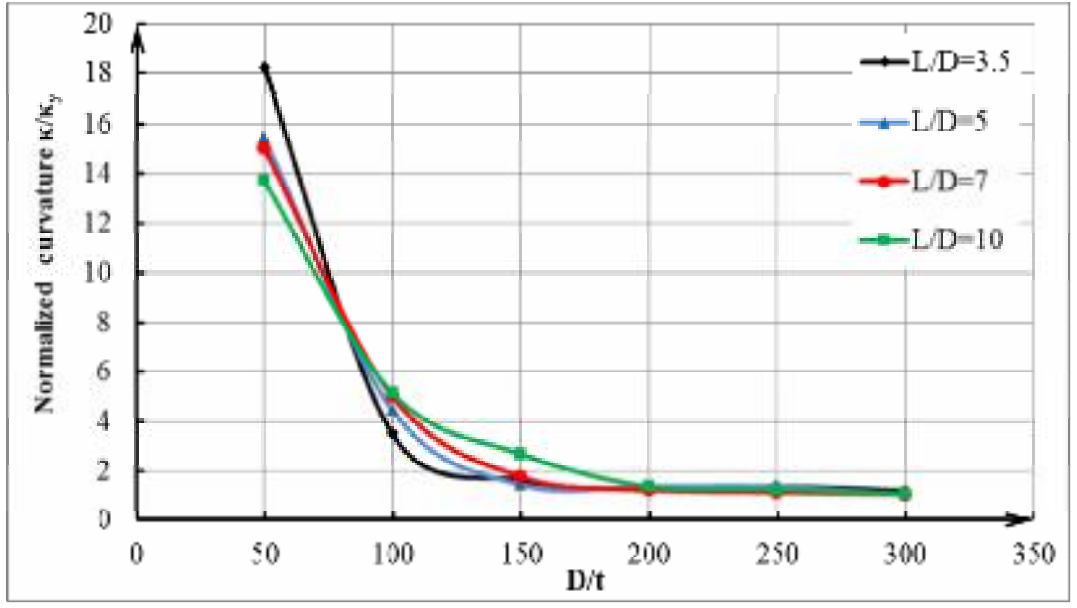

Figure 9: Normalized curvature vs. D/t for all ST37 models.

Fig. 10 shows the normalized moment $\left(M / M_{p}\right)$ curvature $\left(\kappa / \kappa_{y}\right)$ curves of the $L / D=5$ model for the all D/t ratios 50,100,150, 200, 250 and 300. It can be seen that the section rotation (curvature) capacity for the compact section $\mathrm{D} / \mathrm{t}=50$ is the highest capacity. However, the section rotation capacity for the slender section $\mathrm{D} / \mathrm{t}=300$ is the lowest capacity. Moreover, with respect to the section ultimate bending capacity, the D/t model is the highest bending capacity because the $\mathrm{D} / \mathrm{t}$ is within the compact limits. However, the most slender section model $\mathrm{D} / \mathrm{t}=300$ is the lowest bending capacity. Exactly, it is as the pure bending model. In addition, this loading case showed higher strain hardening that the pure bending model because the tube thickness at the loading points is higher than the tube overall thickness for preventing the local failure at these points.

Fig. 11 shows the failure mode shapes of the $\mathrm{L} / \mathrm{D}=5$ model for the all $\mathrm{D} / \mathrm{t}$ ratios $50,100,150$, 200,250 and 300. It can be observed that the $\mathrm{D} / \mathrm{t}=50$ failure mode shape is inward bulge and deformations at the locations of the two concentrated loads. However, the D/t = 100, 150 and 200 failure mode shapes are smooth kink at the mid-span of the tube. Moreover, the $\mathrm{D} / \mathrm{t}=250$ and 300 failure mode shapes are local buckling and sudden collapse. 


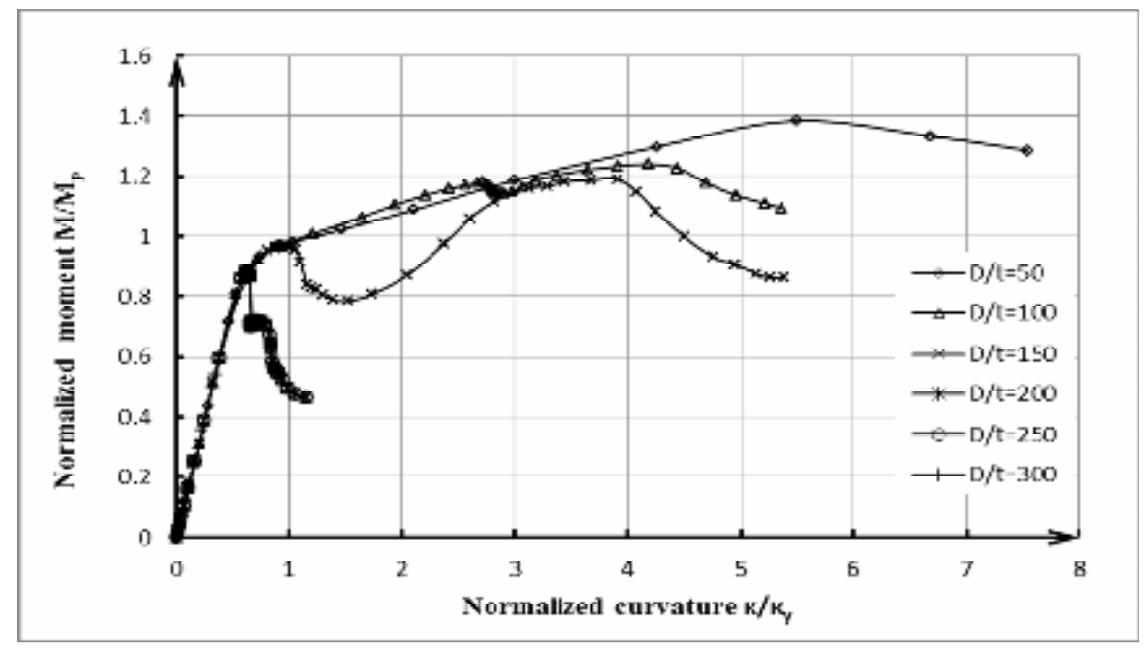

Figure 10: Normalized moment-curvature curves of $L / D=5$ of two loaded points model.
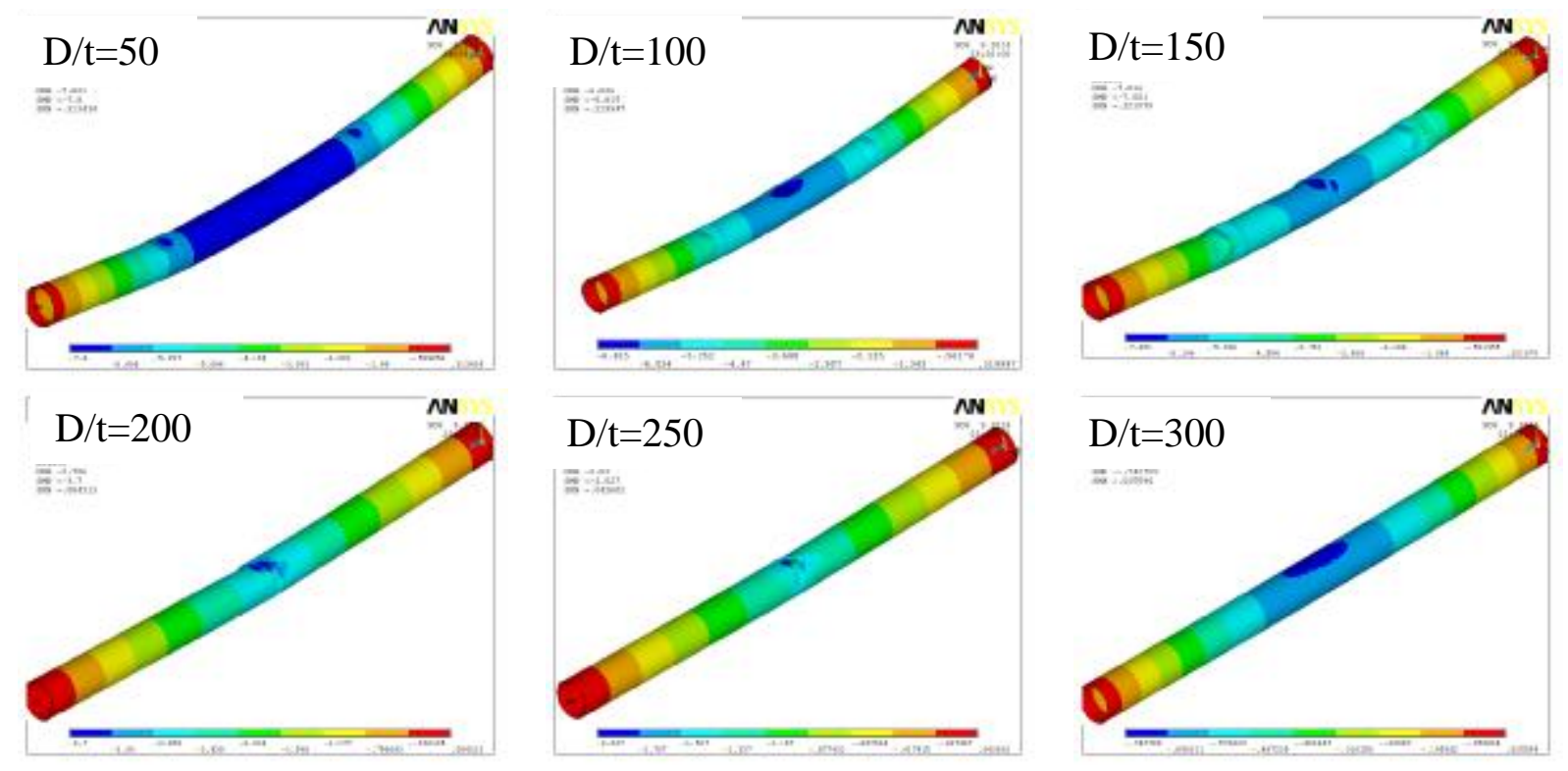

Figure 11: Failure mode shapes of $L / D=5$ of two loaded points model for all $D / t$ ratios.

\subsubsection{Cantilever Model}

Another loading mechanism was performed on L/D $=5$ and ST37 for all D/t ratios. The loading and supporting conditions are cantilever beam with fixed connection at one end and another free end which is loaded by one vertical concentered load. Fig. 12 shows the normalized moment $\left(\mathrm{M} / \mathrm{M}_{\mathrm{p}}\right)$ curvature $\left(\kappa / \kappa_{\mathrm{y}}\right)$ curves of the $\mathrm{L} / \mathrm{D}=5$ model for the all $\mathrm{D} / \mathrm{t}$ ratios $50,100,150,200,250$ and 300. It can be seen that the section rotation (curvature) capacity for the compact section $\mathrm{D} / \mathrm{t}=50$ is the highest capacity. However, the section rotation capacity for the slender section $\mathrm{D} / \mathrm{t}=300$ is the lowest capacity. Moreover, with respect to the section ultimate bending capacity, the D/t model is the highest bending capacity because the $\mathrm{D} / \mathrm{t}$ is within the compact limits. However, the most slender section model D/t $=300$ is the lowest bending capacity. Exactly, it is as the pure bending model and two concentrated loads model. 


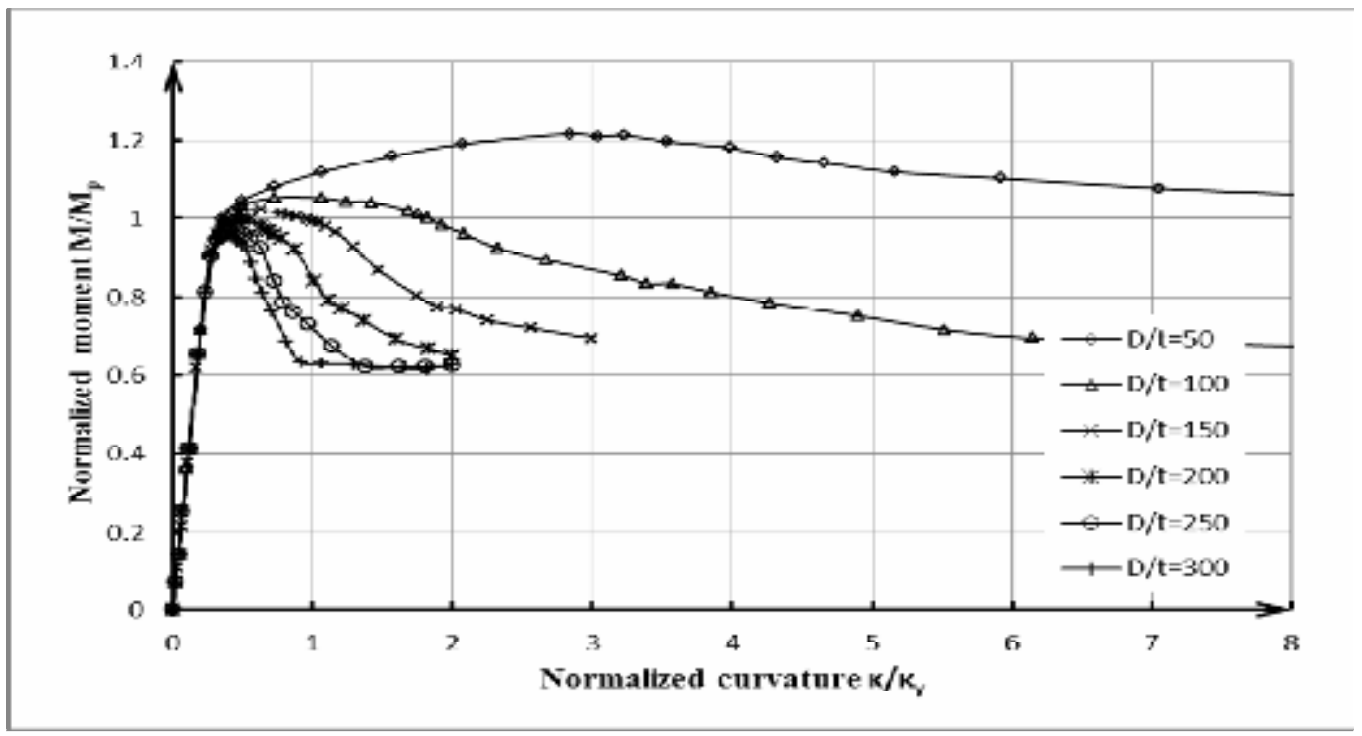

Figure 12: Normalized moment-curvature curves of $\mathrm{L} / \mathrm{D}=5$ of cantilever model.

Fig. 13 shows the failure mode shapes of the $\mathrm{L} / \mathrm{D}=5$ model for the all $\mathrm{D} / \mathrm{t}$ ratios $50,100,150$, 200,250 and 300. It can be observed that the $\mathrm{D} / \mathrm{t}=50$ failure mode shape is inward bulge and deformations at the locations of the maximum bending moment (at the fixed end). However, the $\mathrm{D} / \mathrm{t}=100$ and 150 failure mode shapes are smooth kink. Moreover, the $\mathrm{D} / \mathrm{t}=200,250$ and 300 failure mode shapes are local buckling and sudden collapse.

\subsubsection{Comparison Between the results of the three models.}

The total results of the pure bending, two concentrated loads, and cantilever models are summarized and presented in Fig. 14. The figure shows the tubes ultimate bending for all $\mathrm{D} / \mathrm{t}$ ratios. It can be seen that, for the $\mathrm{D} / \mathrm{t}=50$ and 100 , the ultimate bending strength of the two concentrated loads models is higher than the cantilever models because the failure location is at the two loaded points not at the beam mid-span, so the ovalisation phenomenon didn't affect much the tube capacity. However, for the $\mathrm{D} / \mathrm{t}=150,200,250$ and 300, the ultimate bending strength of the cantilever model is higher than the two concentered loads and pure bending models, because the location of the failure load for the cantilever model is near the supported end, so the welded plate that connected to the tube at this location stiffened the tube and increased its bending strength. However, for the two concentered loads and pure bending, the location of the failure is at the beam mid-span, therefore they wasn't stiffened or supported by any plate in this location. The three models at the slender zone achieved around $80 \%$ of $\mathrm{M}_{\mathrm{p}}$, although they shall be achieved lower moment capacity because these models are geometrical perfect and no residual stresses. However, the experimented tubes in the lab showed lower moment capacity for the non-compact and slender sections.

\section{EXPERIMENTAL TESTING AND COMPARISON}

\subsection{General}

Four full scale circular hollow sections (CHS) were tested to evaluate the behavior of beams under bending moments. Firstly, a series of two full scale cantilever models were tested. Secondly, two full scale (CHS) simple beam models were also tested. It presents the geometry of specimens, tubes diameters, wall thickness, specimen's length, and measured material properties of each specimen. The experimental test apparatus, loading, specimen's instrumentation, observed behaviors, data analysis methods, and measured response of each test specimen are described in the following sections. A comparison is implemented between the full-scale test results of the CHS beams and FEM to assess the matching between these results and evaluate the behavior of CHS beams under bending. 

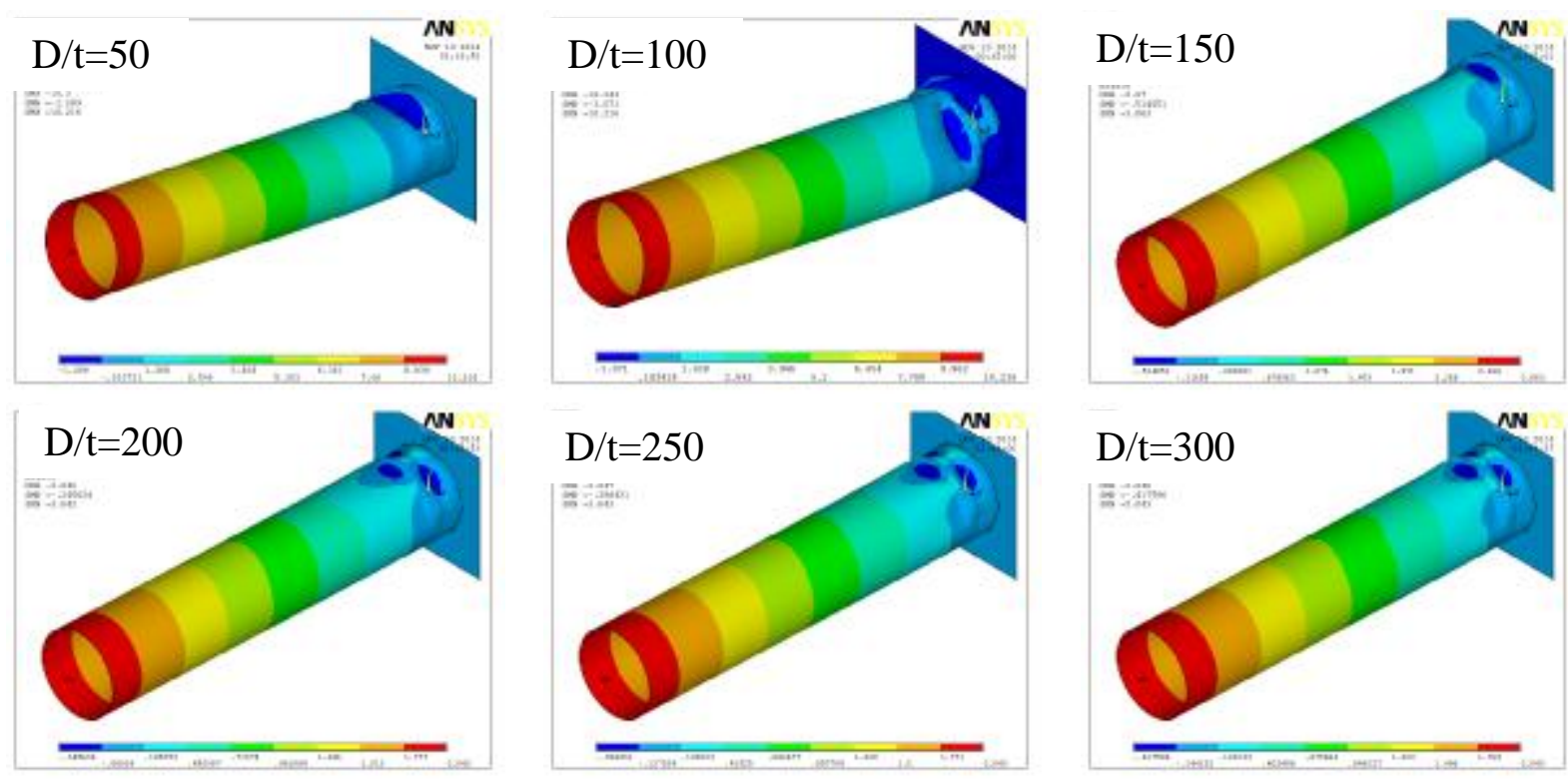

Figure 13: Failure mode shapes of $L / D=5$ of cantilever model for all $D / t$ ratios.

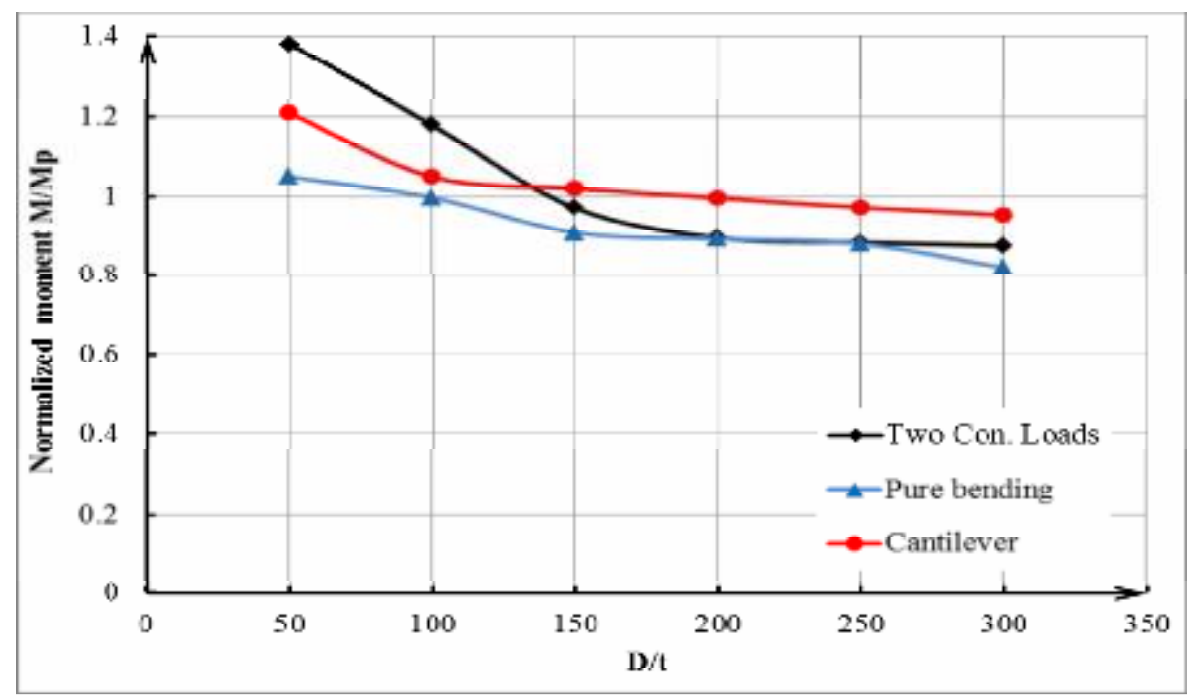

Figure 14: comparison between the three models in bending capacity.

\subsection{Specimens Geometry}

Two cantilever specimens and two simple beams have the same lengths but a different diameter to cover a wide range of beams. The characteristics of the model geometry and properties are described in Table 1.

\subsection{Specimen construction}

Specimens were constructed by using steel sheets and plates as follows:

- Cutting the steel sheets to the required dimensions by a cutting machine.

- Roll the steel sheet by using a rolling machine.

- Welding the rolled steel sheet by longitudinal fillet weld to become a hollow circular beam (hollow tube).

- Welding the tube at the start and end with end plates using circular fillet weld. 
Table 1: Dimensions of specimens.

\begin{tabular}{|c|c|c|c|c|c|c|c|c|c|}
\hline $\begin{array}{c}\text { Specim. } \\
\text { No. }\end{array}$ & $\begin{array}{c}\text { Pure M } \\
\text { Length cm }\end{array}$ & $\begin{array}{c}\text { Diam. } \\
\mathrm{cm}\end{array}$ & $\begin{array}{c}\text { Thick. } \\
\mathrm{cm}\end{array}$ & $\mathrm{L} / \mathrm{D}$ & $\mathrm{D} / \mathrm{t}$ & $\begin{array}{c}\mathrm{I}_{\mathrm{x}}=\mathrm{I}_{\mathrm{y}} \\
\mathrm{cm}^{4}\end{array}$ & $\mathrm{~S}_{\mathrm{x}} \mathrm{cm}^{3}$ & $\mathrm{Z}_{\mathrm{x}} \mathrm{cm}^{3}$ & $\begin{array}{c}\text { Shape } \\
\text { factor }\end{array}$ \\
\hline CB1 & 100 & 16 & 0.2 & 6.25 & 80 & 309.8 & 39.72 & 51.2 & 1.289 \\
\hline CB2 & 100 & 20 & 0.2 & 5 & 100 & 609.7 & 60.97 & 78.41 & 1.286 \\
\hline SB1 & 40 & 7.5 & 0.12 & 5.33 & 62.5 & 18.9 & 5.05 & 6.54 & 1.29 \\
\hline SB2 & 50 & 10 & 0.15 & 5.00 & 66.7 & 56.3 & 11.26 & 14.55 & 1.29 \\
\hline
\end{tabular}

\subsection{Material properties}

Two samples were cut from each specimen and tested in a direct tensile test to find the stress-strain curve of used steel material. The samples of steel were shaped as dog bone sample to be sure that the failure will be at the middle part of sample. The tension test was made by a direct tension machine at the Housing and Building National Research Center and by using strain gauges attached to the tested samples at the middle part. The samples characteristics are listed as following:

- Modulus of elasticity $(\mathrm{E})=2100 \mathrm{t} / \mathrm{cm}^{2}$

- Poisson's ratio $(v)=0.3$

- $\mathrm{F}_{\mathrm{y}}=2.55 \mathrm{t} / \mathrm{cm}^{2}$ for $\mathrm{CB} 1$ and $\mathrm{CB} 2$

- $\mathrm{F}_{\mathrm{y}}=3.7 \mathrm{t} / \mathrm{cm}^{2}$ for $\mathrm{SB} 1$ and $\mathrm{SB} 2$

\subsection{Test Setup}

\subsubsection{Cantilever Model}

The tests were conducted at the Reinforced Concrete Research Lab, Faculty of Engineering, Cairo University. The circular steel hollow beams were prepared and tested under various levels of one vertical concentrated load at the cantilever end. As shown in Fig. 15, the beam was fixed at one end through using connection between the beam end and a vertical column frame by bolting the end plate of the beam and the column flange. The physical test setups for the bending behavior of steel tubes were rested on the earth. One load cell (hydraulic jack) was used to apply the vertical concentrated load gradually at the free end beam on the end plate that connected to the beam by rigid fillet welding connection thus, the force transferred from the load cell through the end plate to the free beam end as a pure concentrated load. The load direction was from down to up, therefore the tension side of the beam was at the lower side and the compression side was the upper side of the beam. So the needed bolts between the end plate which was at the fixed side and the column flange were at the lower side of the end plate to transfer the tension stress from the fixed end plate to the column flange. Moreover, the bolts at the compression side which were at the upper side of the fixed end plate were not needed and the compression stress will transfer from the upper side of end plate to the column flange by bearing. Two LVDT were used to measure the vertical displacement of the end plate which was at the free beam end and the middle span of the beam.

\subsubsection{Two Concentrated loads Model}

Throughout testing, the overall load and vertical displacement in the beam was monitored. Calibrated load cell was used to apply the vertical concentrated load with capacity reaches up to $500 \mathrm{KN}$ as shown in Fig. 16. Four LVDTs were used to measure the vertical displacement at the end and middle of beam with accuracy $0.01 \mathrm{~mm}$. The configuration of LVDT is the same as the cantilever model.

\subsection{Observed Behavior}

Fig. 17 shows the load-displacement curve of the specimen (CB1). The maximum load was 1.3 ton with displacement $28 \mathrm{~mm}$. the curve shape appeared normal and convincing with gradually increasing in the load with the displacement until the ultimate peak load, subsequently when the load reached to the maximum load, the load was decreased with increasing of the displacement. The specimen was at the non-compact zone. 

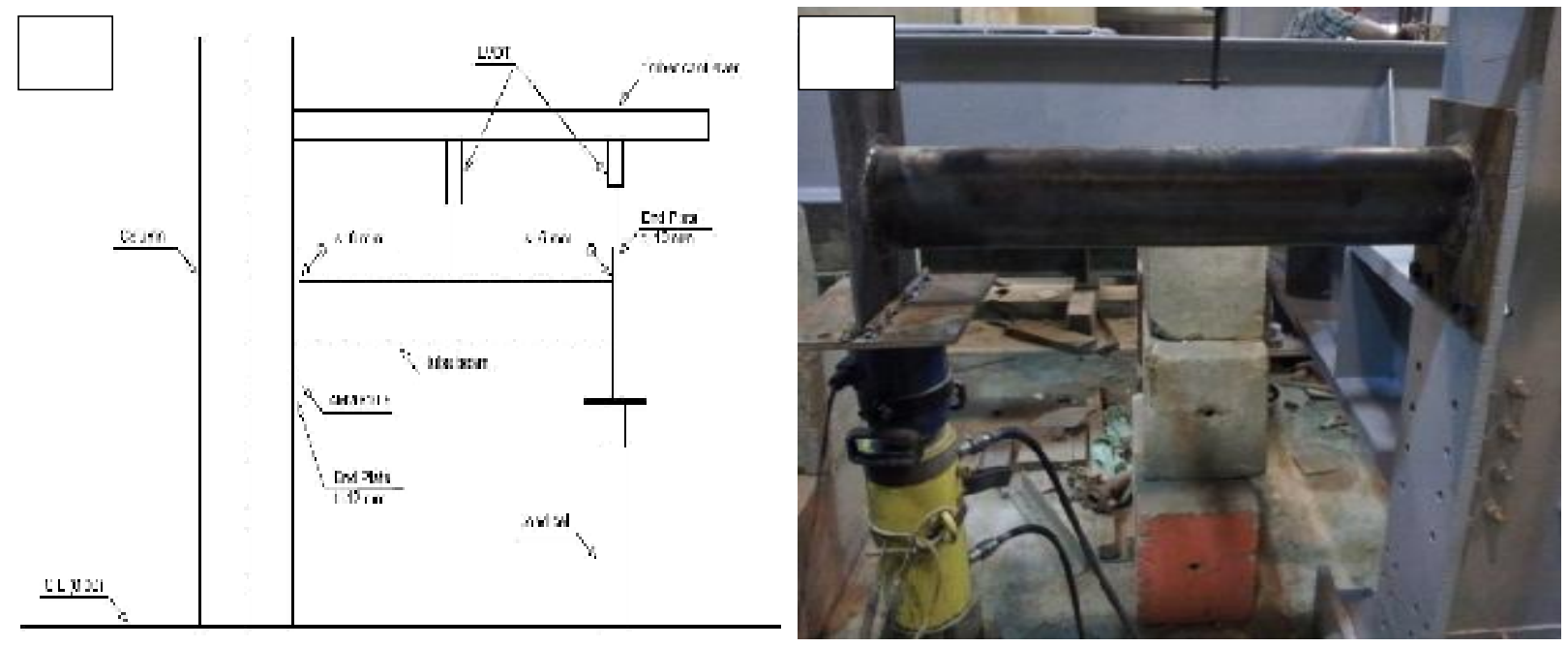

Figure 15: Cantilever beam subjected to one concentrated load at the free end: (a) Schematic view of the test, and (b) Test set-up

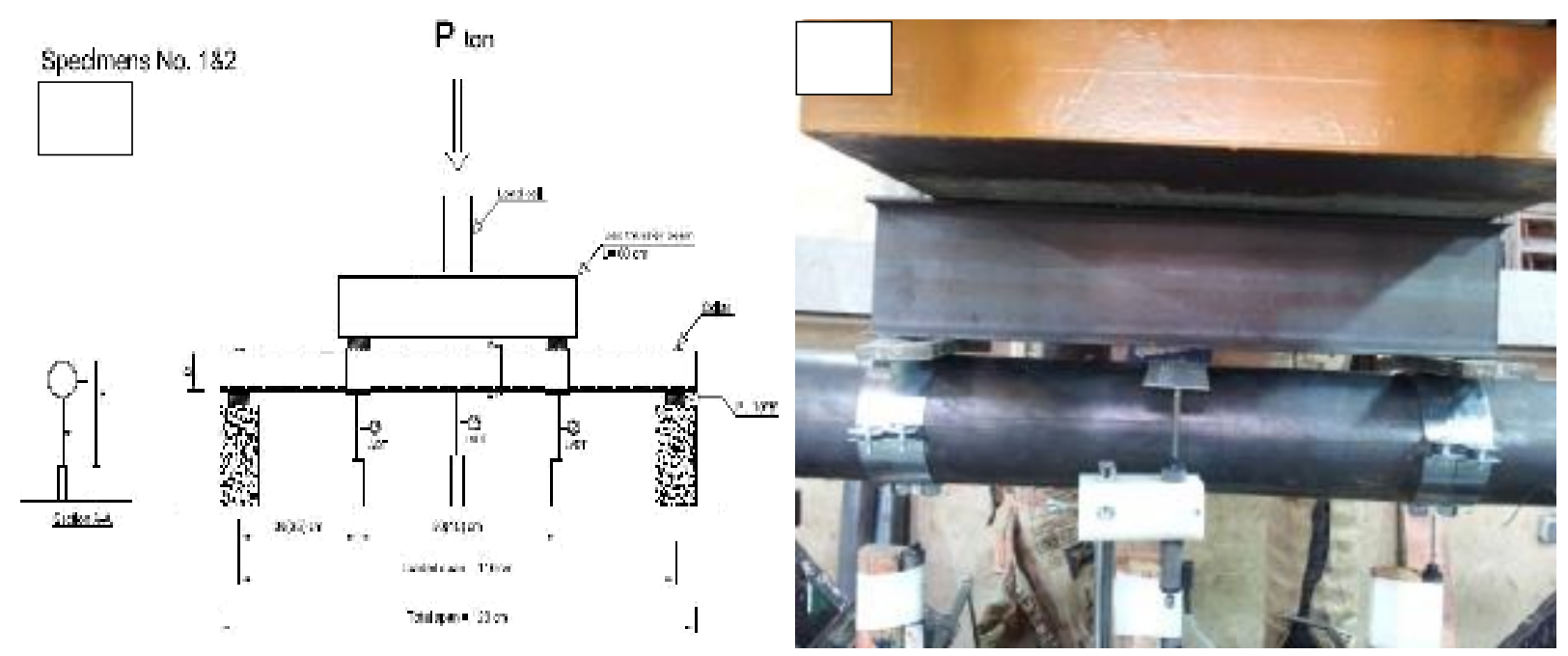

Figure 16: Test of two concentrated loads models: (a) Schematic view, (b) Test setup

The tube was stiffened at its two ends; therefore the plate that was at the tube end was made a confinement for the tube deformations. Subsequently it would have a major effect to control on the tube failure shape. The tube failure was appeared outward wave local buckling at the compression zone of the tube upper side. One clear wave was appeared because the pipe slenderness was at the non-compact zone without any inward local buckling deformations as shown in Fig. 18. Although the specimen (CB1) was in the non-compact zone in all codes slenderness ratios, however it was achieved the tube plastic moment capacity; this maybe because the load condition here was had a main effect on the tube capacity, whereas the tube due to the connection between the end plate at the fixed end and the tube was prevented and confined the tube deformation and ovalisation in the maximum moment location, so the moment capacity of tube was high and almost equal to the tube plastic moment.

The specimen (CB2) dimensions was similar to specimen (CB1), expect for the tube diameter. The specimen (CB2) slenderness limit was 100 that it larger than the specimen (CB1) limit, however it still in the non-compact zone. The observed behavior of the specimen (CB2) was similar to the (CB1). Fig. 19 shows the load-displacement curve of the specimen (CB2). The tubes failure mode shape of the specimen (CB2) was appeared inward and outward local buckling and deformations throughout the upper part of the tubes because it was the tube compression side. Fig. 20 shows the specimen (CB2) failure mode. Here we can see that, the tube bending capacity was in between the tube yield moment and the tube plastic moment. 
Therefore this slenderness ratio was appropriate to be in the non-compact zone. Moreover this result was agreed in all the international codes recommendations.

Both specimens SB1 and SB2 were showed the same failure mode and the global behavior during the test. Figs. 21 and 23 show the load displacement curves of specimens SB1 and SB2, respectively. The curve shape appeared normal and convincing with gradually increasing in the load with the displacement until the ultimate peak load, subsequently when the load reached to the maximum load, the load was slightly decreased with increasing of the displacement. The two specimens were at the non-compact zone.

The specimen SB1 was appeared a combination between the ovalisation and the local buckling at the applying loads locations also as shown in Fig. 22. However, the specimen SB2 failure was appeared the ovalisation of the beam cross section at the applying loads locations as shown in Fig. 24. These behaviors may be because the effect of the collars that under the loads. Here we can see that, the tube bending capacity of both specimens was in between the tube yield moment and the tube plastic moment. Therefore this slenderness ratio was appropriate to be in the non-compact zone. Moreover this result was agreed in all the international codes recommendations. Table 2 shows specimens' slenderness limits $\mathrm{D} / \mathrm{t}$, section slenderness factors $\lambda_{s}$, and buckling coefficient $\alpha$, in addition, the summery of the experimental results and a comparison of the measured ultimate moments with the tubes yield and plastic moments.

\subsection{Comparison between FEM analyses and experiments}

In this part a comparison between the finite element program results (ANSYS) and the experiments results of the cantilever and two concentrated loads models. The comparison is between the load-displacement curve of each specimen and the failure mode shape. The initial imperfections and the residual stresses are not taken into considerations in these models.

For specimen (CB1), there is a good agreement with the FEM and the experiment results. Fig. 17 shows the load-displacement curves of specimen CB1 and we can see that, the curve in the elastic range, the experiment result shows a higher displacement at the same load with respect to the FEM results. According to this comparison we can explain this results that the residual stresses in the compact and non-compact zones have a significant effect on the beam behavior. Here, the residual stresses were produced due to the welding process between the end plate and the tube. The failure modes of the specimen are shown in Fig. 18.

Table 2: Slenderness limits and Comparison between the results

\begin{tabular}{|c|c|c|c|c|c|c|c|c|c|}
\hline $\begin{array}{c}\text { Specim. } \\
\text { No. }\end{array}$ & $\begin{array}{c}\mathrm{F}_{\mathrm{y}} \\
\mathrm{t} / \mathrm{cm}^{2}\end{array}$ & $\mathrm{D} / \mathrm{t}$ & $\begin{array}{c}\text { Slender- } \\
\text { ness } \lambda_{\mathrm{s}}\end{array}$ & $\begin{array}{c}\text { Buckling } \\
\text { coefficient } \\
\alpha\end{array}$ & $\begin{array}{c}\text { Ultimate } \\
\text { moment } \\
\mathrm{M}_{\mathrm{u}}(\mathrm{t} . \mathrm{m})\end{array}$ & $\mathrm{M}_{\mathrm{p}}$ & $\mathrm{M}_{\mathrm{y}}$ & $\mathrm{M}_{\mathrm{u}} / \mathrm{M}_{\mathrm{p}}$ & $\mathrm{M}_{\mathrm{u}} / \mathrm{M}_{\mathrm{y}}$ \\
\hline $\mathrm{CB} 1$ & 2.55 & 80 & 81.6 & 10.3 & 130 & 130.6 & 101.3 & 0.99 & 1.28 \\
\hline CB2 & 2.55 & 100 & 102 & 8.2 & 180 & 200 & 155.5 & 0.9 & 1.16 \\
\hline SB1 & 3.7 & 62.5 & 92.5 & 9.1 & 22.75 & 24.2 & 18.7 & 0.94 & 1.217 \\
\hline SB2 & 3.7 & 66.7 & 98.67 & 8.5 & 46.5 & 53.85 & 41.67 & 0.86 & 1.116 \\
\hline
\end{tabular}

Where: $\quad \lambda_{\mathrm{s}}=(\mathrm{D} / \mathrm{t}) \cdot\left(\mathrm{F}_{\mathrm{y}} / 2.5\right) \quad \alpha=\left(\mathrm{E} / \mathrm{F}_{\mathrm{y}}\right) /(\mathrm{D} / \mathrm{t})$ 


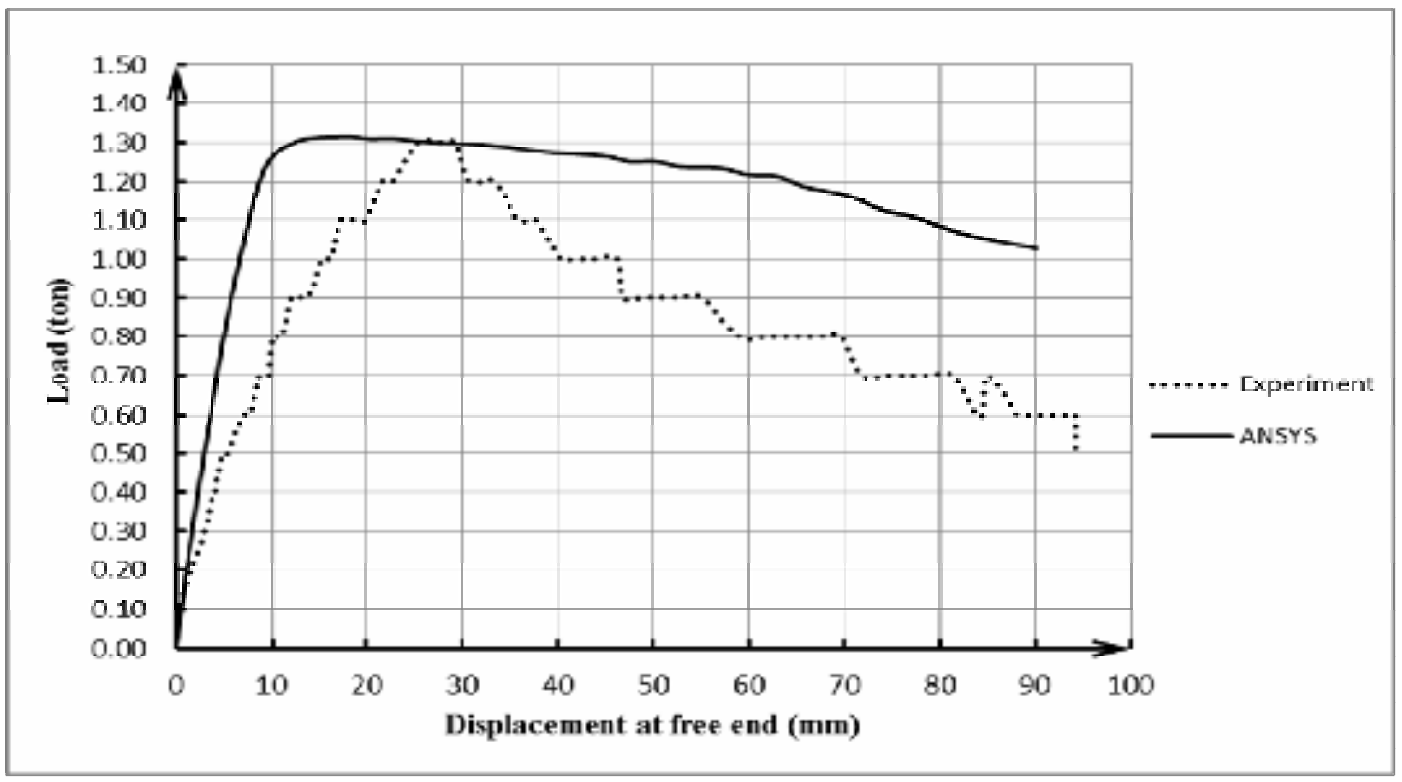

Figure 17: Load-displacement curves of specimen CB1.

For specimens $\mathrm{CB} 1$ and $\mathrm{CB} 2$, there is a good agreement with the FEM and experiment results for specimen CB2. Fig. 19 shows the load displacement curves of specimen CB2 with its two samples. We can notice that, the ultimate load of FEM is higher than the experiment result. For specimen (SB1), there is a good correlation between the FEM and experiment results for specimen SB1. Fig. 21 shows a comparison between the FEM and experiment load displacement curves and both curves are matched from the beginning to the ultimate load. It can be seen that the FEM ultimate load is higher than experimental load. Moreover there is a good similarity between both failure modes as shown in Fig. 22.

When the slenderness limit become higher, the different between the tube load capacities became higher. Moreover, the load displacement curves are matched in the beginning of the curve then the experiments results showed a higher displacement at the ultimate load with respect to the FE displacement. So the residual stresses and the initial imperfection are more significant for the non-compact than compact sections. The failure modes of the specimen are shown in Fig. 20.
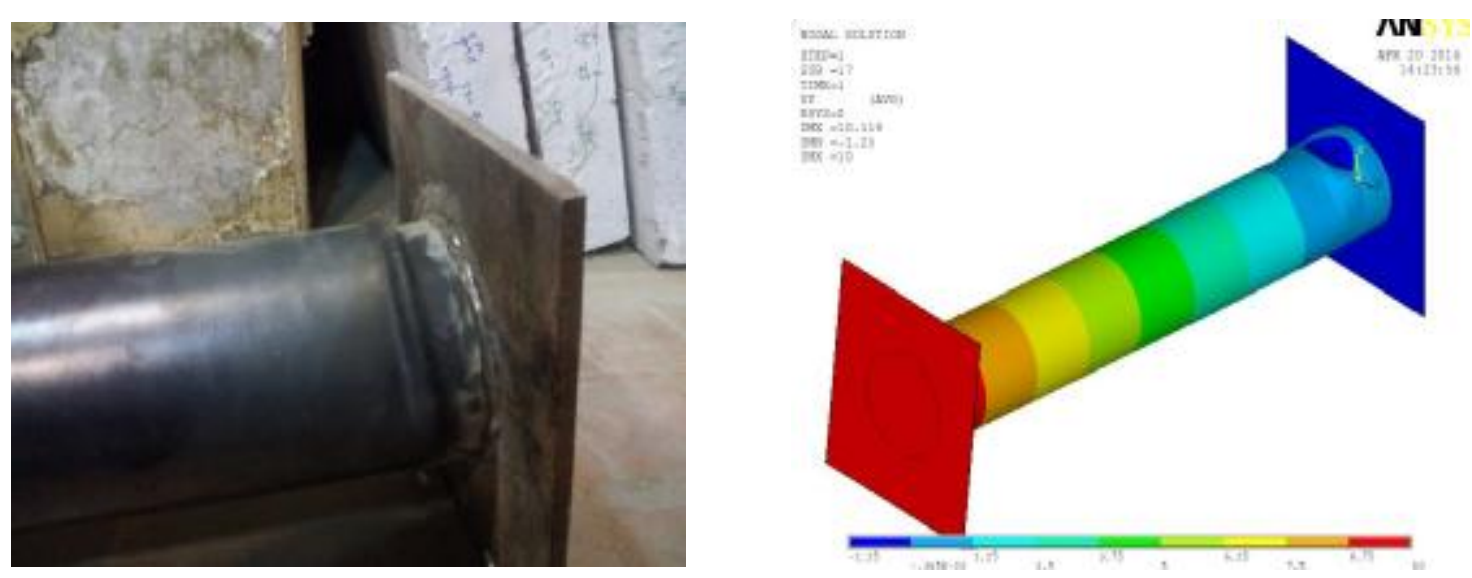

Figure 18: Failure mode shapes of CB1 


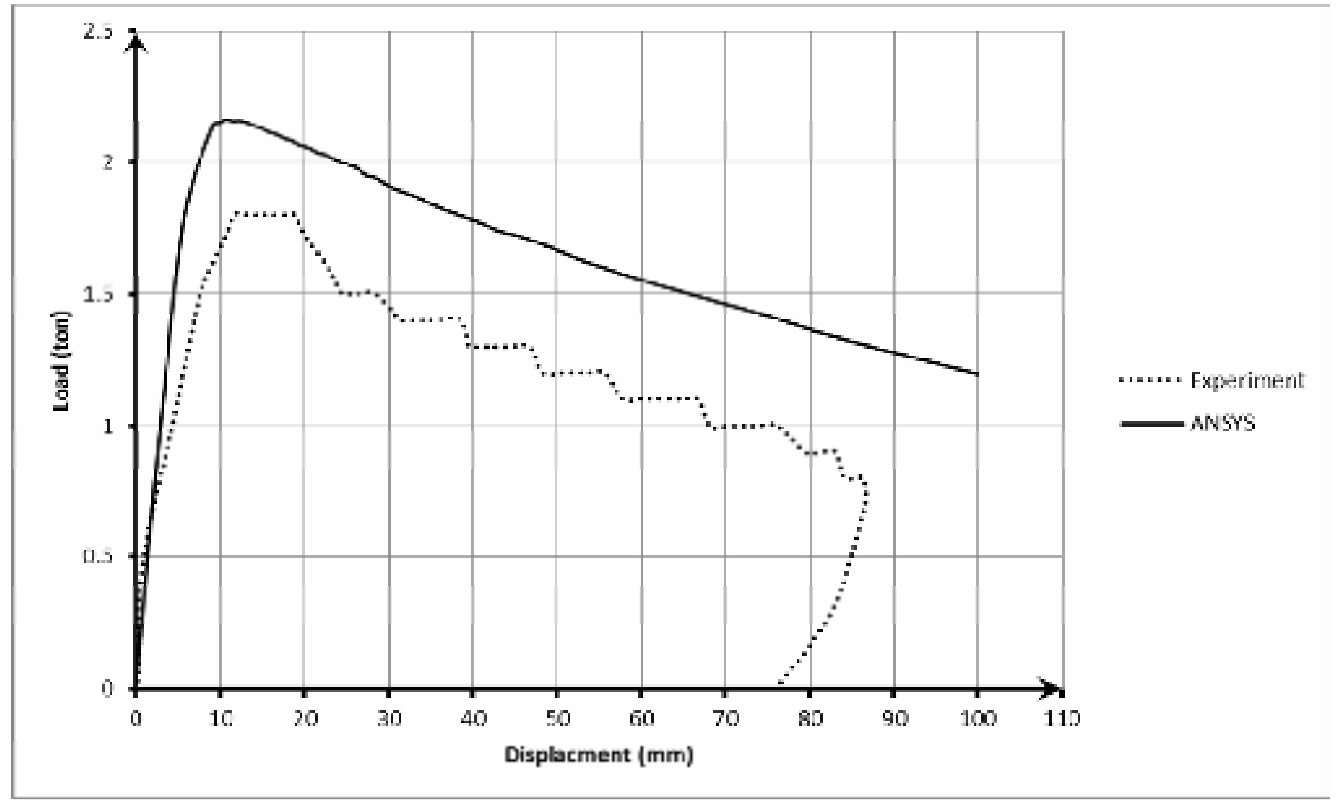

Figure 19: Load-displacement curves of specimen CB2.
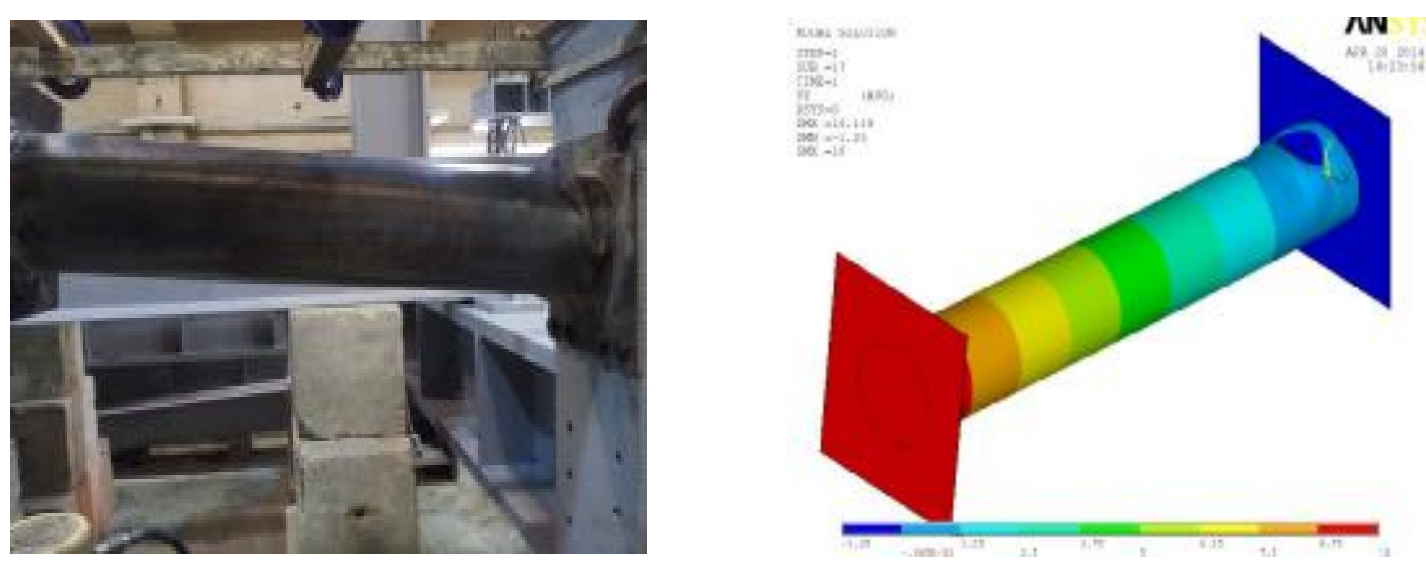

Figure 20: Failure mode shapes of CB2.

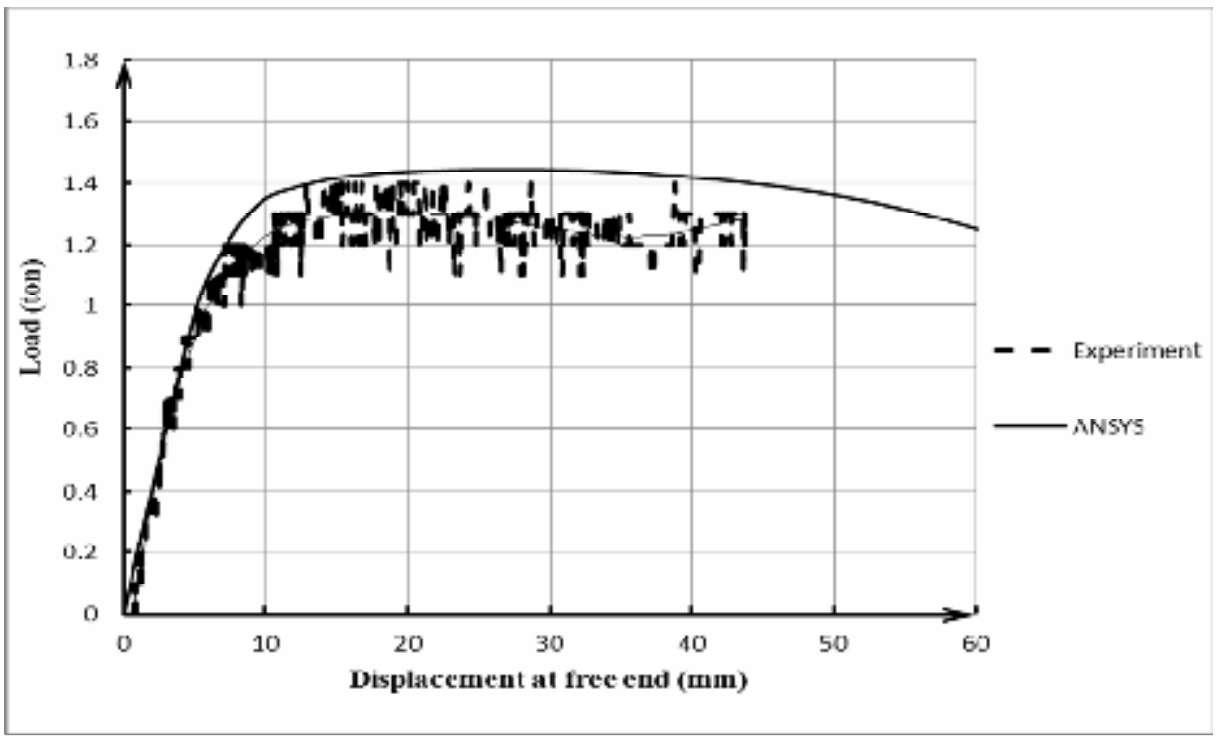

Figure 21: Load-displacement curves of specimen SB1. 
For specimen SB1, there is a good correlation between the FEM and experiment results for specimen SB2. Fig. 23 shows a comparison between the FEM and experiment load displacement curves and both curves are matched from the beginning of the curve but after that the experiment result give higher displacement at the ultimate load than the FEM result. However, the FEM ultimate load is higher than experiments load. Moreover there is a good similarity between both failure modes as shown in Fig. 24. code equation in the non-compact zone shows unsafe moment capacity vs. some experimental results. Moreover, the slender zone is more conservative.

\subsection{Comparison between the results of experiments}

Fig. 25 shows a comparison between the experiments results of this research, the international codes and the most previous experimental works of bending capacity of circular steel hollow sections vs. the section slenderness ratio $\lambda_{\mathrm{s}}$ and the yield stress ranges from 1.9 to $3.7 \mathrm{t} / \mathrm{cm}^{2}$. The evaluation of the Egyptian and international codes can be summarized as follows:

$\ddot{y}$ The Egyptian code: there is a good agreement with the results in the compact zone because the tube capacity is less than the plastic moment due to the ovalisation phenomena. However, the

$\ddot{y}$ The American code AISC (2010): the bending capacity in the compact zone does not take into consideration the reduction that takes place in the tube cross section due to ovalisation. Moreover, for the non-compact and slender zones the moment capacity vs. most of experimental results is unsafe. Therefore, this code is not conservative and gives higher bending capacity than the actual capacity.

$\ddot{y}$ ASCE (2011): it is very conservative in the compact zone because it gives only the yield moment capacity. However, it is good in the non-compact zone. But in the slender zone, it is limited and cannot reach to far limits.

$\ddot{y}$ The Australian code AS4100: this code is the best code based on this study because it shows good agreement with experimental results expects for the compact zone where it presents the full plastic moment as the tube capacity and doesn't take the reduction in the tube capacity due to the ovalisation into consideration.

Based on this comparison and on Fig. 25, it can be concluded that: firstly, for the compact zone, the main obstruction that prevents achieving the tube full plastic capacity is the ovalisation phenomena so we suggest considering that the $\mathrm{M}_{\mathrm{p}}$ equal to 1.15 instead of 1.273 of $\mathrm{M}_{\mathrm{y}}$. Secondly, for the non-compact and slender zones, the tube capacity and slenderness limits should be taken to be at the lower bound of the experimental results of this study and most previous work.

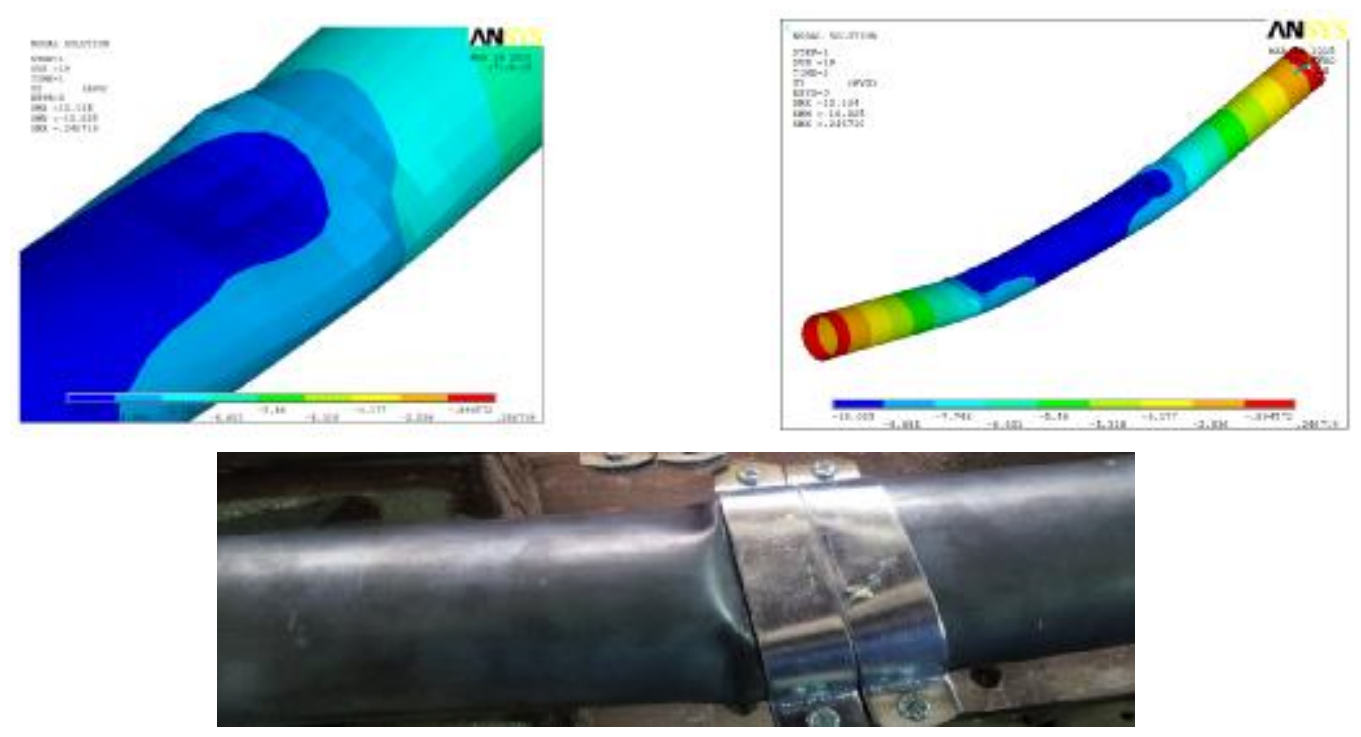

Figure 22: Failure mode shapes of SB1. 


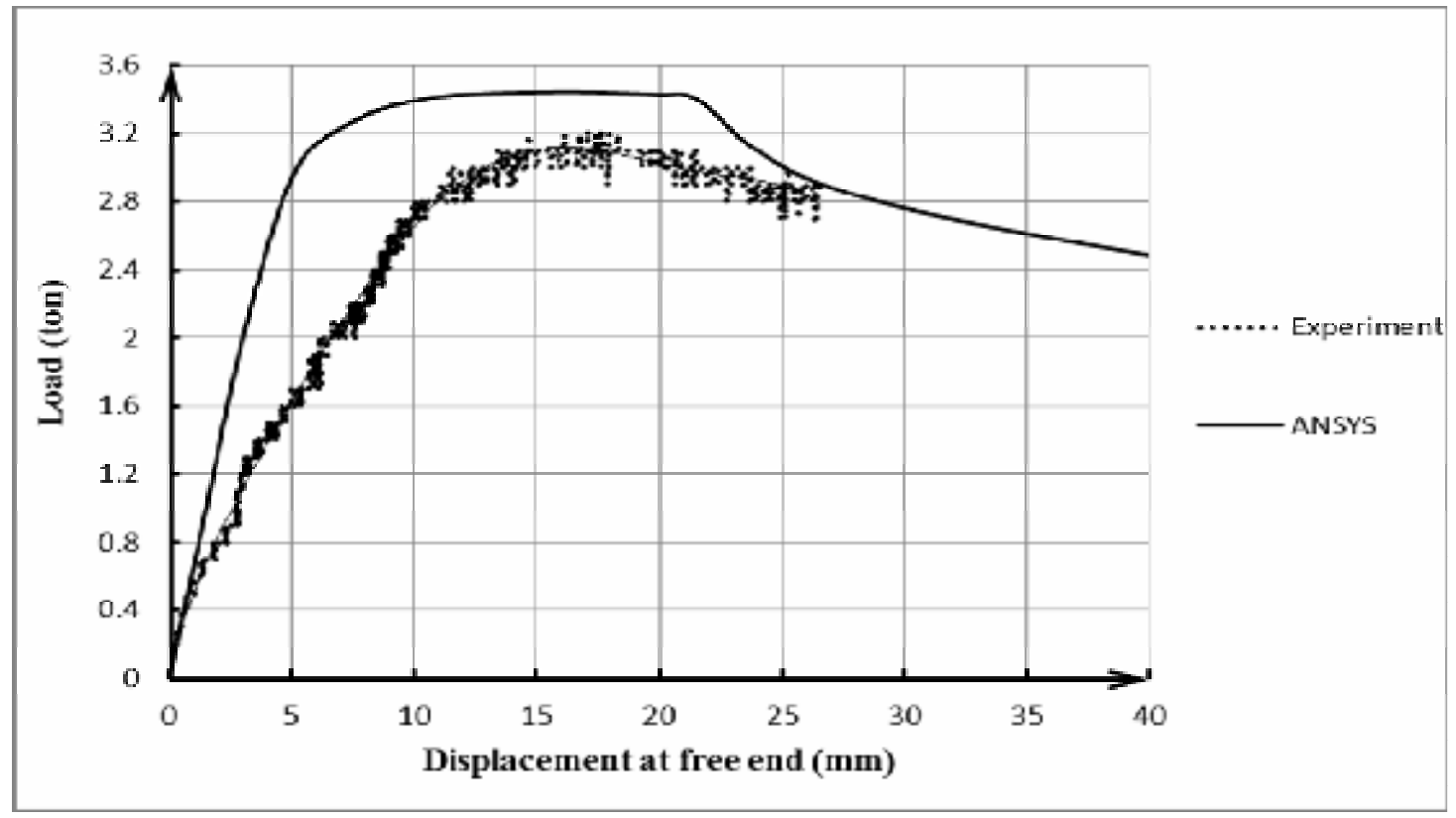

Figure 23: Load-displacement curves of specimen SB2.
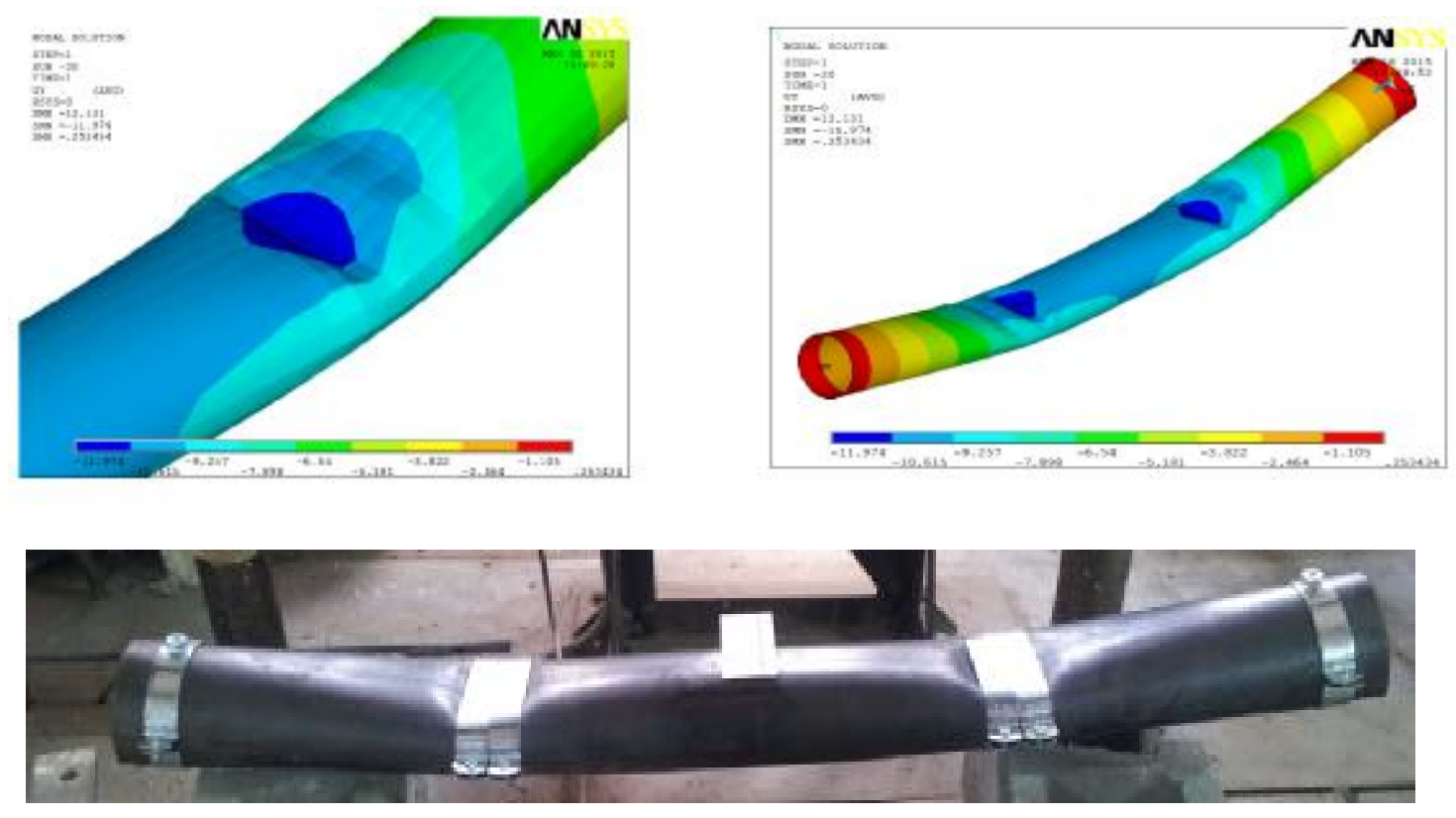

Figure 24: Failure mode shapes of SB2 


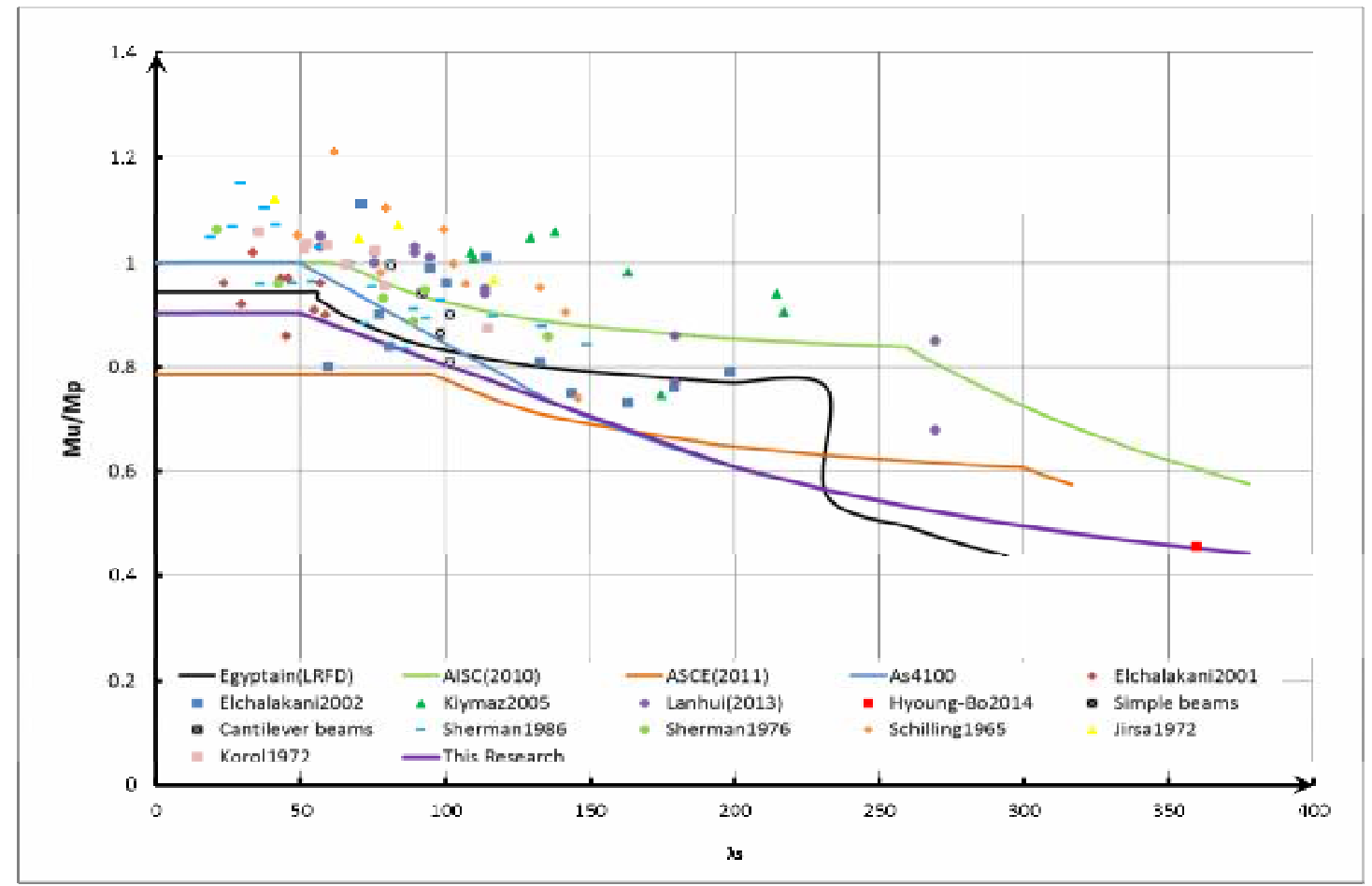

Figure 25: $M_{u} / M_{p}$ vs. Section slenderness relationships

From Figure 25 , the first point under the $1.15 \mathrm{M}_{\mathrm{y}}$ has $\lambda_{\mathrm{s}}$ larger than 50 . Therefore, the suggested limit that separates compact from non-compact zone is $\lambda_{s}=50$. In addition, the first point under the $\mathrm{M}_{\mathrm{y}}$ has $\lambda_{\mathrm{s}}$ larger than 140, so the recommended limit which separates between the non-compact and slender sections is $\lambda_{\mathrm{s}}=140$. This study (Gomaa 2015) also suggests new proposed equations (Eq. 3, 4 and 5) that predict the tubes moment capacity using the new proposed slenderness limits:

$$
\begin{array}{lll}
M=1.15 F_{y} S_{x} & \text { (3) For compact sections: } & \lambda_{\mathrm{s}}<50 \\
M=\left(0.94+\frac{140-\lambda_{s}}{90} 0.21\right) F_{y} S_{x} & \text { (4) For non-compact sections: } & 50<\lambda_{\mathrm{s}}<140 \\
M=\left(\frac{124}{\lambda_{s}}\right)^{0.5} F_{y} S_{x} & \text { (5) For slender sections: } & \lambda_{\mathrm{s}}>140
\end{array}
$$

\section{CONCLUSIONS}

An assessment is performed to predict the bending capacity of circular steel hollow sections (CHS). Several parameters were studied, namely: $\mathrm{F}_{\mathrm{y}}, \mathrm{D} / \mathrm{t}, \mathrm{L} / \mathrm{D}$, loading and supporting conditions. Both material and geometrical nonlinearities are taken into consideration. In addition, four full-scale circular steel hollow beams are tested to verify the actual bending capacity of common thin tubes. The main conclusions are:

\section{Based on the results of FEM}

$\ddot{y}$ The effect of changing L/D has no significant effect on the pipe bending capacity (the effect is less than $5 \%$ and random).

$\ddot{y}$ Brazier's ovalisation effect is significant for compact sections while Timoshenko's equation is more significant for slender sections. Neither equation considers material nonlinearity. 
$\ddot{y}$ The actual moment capacity of the compact tubes can be fairly predicted because the finite element program can take into consideration the reduction that takes place in the tube inertia during the loading (ovalisation).

$\ddot{y}$ On the other hand, for non-compact and slender tubes, the actual tube moment capacity cannot be predict because these sections are very sensitive for initial imperfections and residual stresses that take place during manufacturing, transporting and handling.

\section{Based on the results of experiments}

$\ddot{y}$ For compact tubes: the moment capacity of is less than the plastic moment $\mathrm{M}_{\mathrm{p}}$ due to ovalisation. Therefore, we can predict the tube bending capacity by assuming that $\mathrm{Z}_{\mathrm{x}}=$ $1.15 * \mathrm{~S}_{\mathrm{x}}$ (instead of $1.273 * \mathrm{~S}_{\mathrm{x}}$ ).

$\ddot{y}$ For non-compact tubes: the moment capacity is affected by both ovalisation and local buckling. Therefore, initial imperfections and residual stresses have significant effect on the capacity.

$\ddot{y}$ For the slender tubes: the moment capacity is controlled mainly by local buckling. Therefore, it is very sensitive for the initial imperfection.

$\ddot{y} \quad$ For the tested cantilever beams, the moment capacity is larger than the plastic moment or equal to it because no loss of inertia due to the ovalisation at fixed end. So, we can take the full plastic moment as tube capacity without any reduction $\left(\mathrm{Z}_{\mathrm{p}}=1.273 * \mathrm{~S}_{\mathrm{x}}\right)$.

$\ddot{y}$ The residual stresses due to weld near the fixed support triggered local buckling for the non-compact.

$\ddot{y}$ Especially for slender tubes, moment capacity and failure location are very sensitive to initial imperfections.

\section{REFERENCES}

1. ANSI/AISC 360-10 (2010). Specification for Structural Steel buildings. American Institute of Steel Construction, Chicago, Ill.

2. Standards Association of Australia (SAA), (1998). Steel Structures Code, AS4100.

3. ASCE/AWEA RP (2011). "Recommended Practice for Compliance of Large-based Wind Turbine Support Structures". Reston, VA and Washington, DC.

4. Egyptian Code of Practice for Steel Construction, (Load and Resistance Factor Design) (2008). Code No. ECP 205, HBRC, Giza, Egypt.

5. Brazier, L. G. (1927). "On the flexure of thin cylindrical shells and other "thin" sections". Proceedings of the Royal Society, London (series A), Vol. 14, pp. 104-116.

6. Timoshenko, S. P. (1961). "Theory of elastic stability". McGraw-Hill, New York.

7. Sherman, D. R. (1976). "Tests of circular tubes in bending". Journal of structural Division ASCE, pp. 2181-95.

8. Sherman, D. R. (1986). "Inelastic flexural buckling of cylinders". Steel Structures, Pavlovic MN, editor, proceedings of the invited papers for the international conference of recent research advance and their applications to design, Budva, Yugoslavia.

9. Schilling, G. S. (1965). "Buckling strength of circular tubes". Journal of the structural division, ASCE, pp. 325-348.

10. Jirsa, J. O., Lee, F., Wilhoit, J. C. and Merwin, J. E. (1972). ”Ovaling of pipelines under pure bending". Proceedings of the offshore technology conference, Houston, Texas.

11. Korol, R.M., Huboda, J. (1972). "Plastic behaviour of hollow structural sections". Journal of the structural division ASCE, pp. 1007-23.

12. Elchalakani, M., Zhao, X. L. and Grzebieta, R. H. (2001). "Plastic slenderness limits for cold formed circular hollow sections". Australian Journal of Structural Engineering, Vol. 3, No. 3, PP. 127-141.

13. Cimpoeru, S. J., Murray, N. W. (1993). "The large-deflection pure bending properties of a square thin-walled tube". International Journal of Mechanical Science, Vol. 35, Issues 3-4, pp. 247-256.

14. Elchalakani, M., Zhao, X.L., and Grzebieta, R. H. (2002). "Bending tests to determine slenderness limits for cold-formed circular hollow sections". Vol. 58, Issue 11, pp. 1407-1430. 
15. Kiymaz, G. (2005). "Strength and stability criteria for thin-walled stainless steel circular hollow section members under bending". Thin-walled structures, Vol. 43, pp. 1534-1549.

16. Kiymaz, G., Coskun, E. and Cosgun C. (2007). "Behavior and design of seam-welded stainless steel circular hollow section flexural members". Journal of structural engineering, ASCE.

17. ABAQUS version 6.10.1 (2011). 3D Simulation Software: Simulia - Dassault Systemes

18. https://www.3ds.com/products-services/simulia Dassault systemes simulia corp.

19. Sadowski, A. J., Rotter, J. M. (2013). "Solid or shell finite elements to model thick cylindrical tubes and shells under global bending". International Journal of Mechanical Sciences, Vol. 74, pp. 143-153.

20. Guo, L., Yang, S. and Jiao, H. (2013). "Behavior of thin-walled circular hollow section tubes subjected to bending". Thin-Walled Structures, Vol. 37, pp. 281-289.

21. ANSYS Inc. (2007), release 11.0. Engineering Simulation \& 3d Design Software: Ansys https://www.ansys.com

22. Sim, H. B., Prowell, I., Elgamal, A. and Uang, C. M. (2014). "Flexural tests and associated study of a full-scale $65-\mathrm{KW}$ wind turbine tower". Journal of structural engineering, Vol. 140, Issue 5.

23. Gomaa, E. Y. (2015). "Analytical and Experimental Assessment of Nonlinear Behavior for Circular Steel Hollow Sections under Bending”. M.Sc. Thesis, Faculty of Engineering, Cairo University, Giza, Egypt. 